\title{
Spreading Depolarizations Occur in Mild Traumatic Brain Injuries and Are Associated with Postinjury Behavior
}

\author{
Johann M. Pacheco, Ashlyn Hines-Lanham, Claire Stratton, Carissa J. Mehos, Kathryn E. McCurdy, \\ Natalie J. Pinkowski, Haikun Zhang, C. William Shuttleworth, and Russell A. Morton
}

https://doi.org/10.1523/ENEURO.0070-19.2019

Department of Neurosciences, University of New Mexico School of Medicine, Albuquerque, NM 87131

\begin{abstract}
Millions of people suffer mild traumatic brain injuries (mTBls) every year, and there is growing evidence that repeated injuries can result in long-term pathology. The acute symptoms of these injuries may or may not include the loss of consciousness but do include disorientation, confusion, and/or the inability to concentrate. Most of these acute symptoms spontaneously resolve within a few hours or days. However, the underlying physiological and cellular mechanisms remain unclear. Spreading depolarizations (SDs) are known to occur in rodents and humans following moderate and severe TBIs, and SDs have long been hypothesized to occur in more mild injuries. Using a closed skull impact model, we investigated the presence of SDs immediately following a mTBI. Animals remained motionless for multiple minutes following an impact and once recovered had fewer episodes of movement. We recorded the defining electrophysiological properties of SDs, including the large extracellular field potential shifts and suppression of high-frequency cortical activity. Impact-induced SDs were also associated with a propagating wave of reduced cerebral blood flow (CBF). In the wake of the SD, there was a prolonged period of reduced CBF that recovered in approximately $90 \mathrm{~min}$. Similar to SDs in more severe injuries, the impact-induced SDs could be blocked with ketamine. Interestingly, impacts at a slower velocity did not produce the prolonged immobility and did not initiate SDs. Our data suggest that SDs play a significant role in mTBls and SDs may contribute to the acute symptoms of mTBls.
\end{abstract}

Key words: cerebral blood flow; closed skull impact; concussion; cortical spreading depression; electrophysiology; laser speckle contrast imaging

\section{Significance Statement}

Millions of people suffer from concussions every year and repeated concussions are associated with chronic traumatic encephalopathy (CTE). Spreading depolarizations (SDs) are propagating waves of brain tissue depolarization that have been associated with strokes, subarachnoid hemorrhages, and moderate to severe brain injuries. SDs have long been hypothesized to occur in mild brain injuries, but have not been recorded. Our studies are the first to directly record the electrophysiological properties of SDs following a closed skull impact, and suggest that SDs may contribute to the acute symptoms of mild traumatic brain injuries (mTBls).

Received February 26, 2019; accepted November 11, 2019; First published November 20, 2019.

The authors declare no competing financial interests.
Author contributions: J.M.P., A.H.-L., C.S., C.J.M., K.E.M., N.J.P., H.Z., and R.A.M. performed research; J.M.P., A.H.-L., C.S., C.J.M., K.E.M., N.J.P., and R.A.M. analyzed data; C.W.S. and R.A.M. designed research; C.W.S. and R.A.M. wrote the paper. 


\section{Introduction}

Concussions are serious injuries and are now considered to be mild traumatic brain injuries (mTBls). It is estimated that there are $\sim 3.8$ million sports-related concussions each year (Clay et al., 2013). This is most likely an underestimate due to under reporting and/or a lack of a diagnosis. Concussions are often defined by the immediate and transient symptoms associated with impaired neurologic function. Most individuals recover within a few days or weeks, but $\sim 20-30 \%$ suffer from a constellation of prolonged symptoms including the inability to concentrate, dizziness, headaches, behavioral deficits, cognitive deficits, and/or sleep disruption for months (Silver et al., 2009; Brent and Max, 2017). In addition to cognitive and behavioral deficits, repeated mTBls are associated with diffuse axonal injury, accumulation of amyloid precursor protein (APP), increases in amyloid- $\beta$, diffuse $A \beta$ plaques, which collectively are used to diagnose chronic traumatic encephalopathy (CTE; for review, see DeKosky et al., 2013). A mTBI can disrupt cellular membranes, intracellular scaffolding, axonal fibers, synaptic connections, cerebral blood flow (CBF), and the blood brain barrier (Chodobski et al., 2011; Giza and Hovda, 2014). mTBls are most commonly associated with reduced CBF (McLaughlin and Marion, 1996; Dietrich et al., 2000; Giri et al., 2000) and neurochemical and ion imbalances (Denny-Brown and Russell, 1941; Ward, 1964; Takahashi et al., 1981; West et al., 1982; Kubota et al., 1989; Katayama et al., 1990; Yoshino et al., 1991). Recovery from this imbalance is metabolically demanding and is likely to occur in the presence of reduced blood flow. This imbalance has been described as a neurometabolic cascade and can take days to weeks to fully recover (Giza and Hovda, 2014). It has been suggested that the underlying component of the neurometabolic cascade could be spreading depolarizations (SDs), but the role of SDs in mild injuries remains unclear.

SDs are propagating waves of complete tissue depolarization that result in a transient suppression of cortical activity lasting multiple minutes. SDs were first characterized in rabbits (Leao, 1944) and later extensively studied in rodents (Buresova, 1956; Bures and Buresova, 1960; Fifkova et al., 1961; Krivanek, 1961; Monakhov et al., 1962; Ruediger et al., 1962; Ward and Sinnett, 1971; Maxson and Cowen, 1977). Over 10 years of clinical recordings have implicated SDs in humans following traumatic brain injuries and strokes (Strong et al., 2002, 2007;

This work was supported by the National Institutes of Health Grant 1P20GM109089 and NS106901 and by the University of New Mexico Health Sciences Center Undergraduate Pipeline Network.

Acknowledgements: We thank Dr. Fernando Valenzuela for helpful discussions and critically reading this manuscript and Katelyn Reinhart for technical assistance and helpful discussions throughout this research. We also thank the Center for Brain Recovery and Repair's Preclinical Core.

Correspondence should be addressed to Russell A. Morton at ramorton@salud.unm.edu.

https://doi.org/10.1523/ENEURO.0070-19.2019

Copyright (C) 2019 Pacheco et al.

This is an open-access article distributed under the terms of the Creative Commons Attribution 4.0 International license, which permits unrestricted use, distribution and reproduction in any medium provided that the original work is properly attributed.
Hartings et al., 2008, 2011). SDs have also been linked to the visual auras of migraine sufferers (Lauritzen et al., 1983; Cao et al., 1999; Hadjikhani et al., 2001). It has long been thought that SDs occur during mTBls due to the similarities in the neurochemical imbalance and disruptions in CBF (Meyer and Denny-Brown, 1955; Zachar and Zacharová, 1958, 1961; Kubota et al., 1989; West et al., 1982; Watanabe and Noriaki, 2002). However, exciting new data from Bouley and colleagues described the hemodynamic responses that are associated with SDs immediately following an injury (Bouley et al., 2019). The hemodynamic response immediately following the injury was followed by a period of prolonged post-SD oligemia and was associated with neurologic dysfunction hours after the injury (Bouley et al., 2019). The electrophysiological properties of SDs have been recorded in more invasive models of mTBls (i.e., fluid percussion and cortical impact; Takahashi et al., 1981; Kubota et al., 1989; Sunami and Nakamura, 1989; Nilsson et al., 1993; Sword et al., 2013). However, direct electrophysiological recordings of SDs have not been established in a mild closed skull injury model.

In this study, we use a mouse model of $\mathrm{mTBI}$ that produces concussion-like behavior, but does not result in gross tissue damage. SDs are defined by their electrophysiological properties of a large extracellular field potential shift and suppression of high-frequency cortical activity. We have directly recorded these electrical events in our model, and have correlated the presence of SDs to the behavioral phenotype of our model.

\section{Materials and Methods}

\section{Animals}

All animal procedures were performed in accordance with the authors' University Institutional Animal Care and Use Committee. Wild-type C57/BI6 mice were purchased from The Jackson Laboratory. To model late adolescence and early adulthood we used mice between eight and 14 weeks of age. Both male and female mice were used for these studies and were analyzed separately to identify any sex related differences before combining. Our preliminary analyses did not indicate any differences between the sexes, so all of our data sets include both male and female mice in equivalent numbers.

\section{mTBI model}

The model used in these studies was adapted from previously published work using controlled cortical impactors without craniotomy (Lighthall, 1988; Shitaka et al., 2011; Main et al., 2017). The modification here is that the motion of the head and body was not restricted during the impact to allow for coup and countercoup motion. Animals were anesthetized with either isoflurane (2-4\%) or urethane $(1.5 \mathrm{mg} / \mathrm{g})$. The anesthetized animal was placed on a custom Kaizen foam (FastCap) platform directly beneath the impactor without restricting the body or head. The Impact One controlled impactor (Leica Biosystems) was used to deliver the impact to the intact skin and skull. The foam platform and impactor are shown in Figure $1 A$. The animal's head was not restrained during the impact. 
A

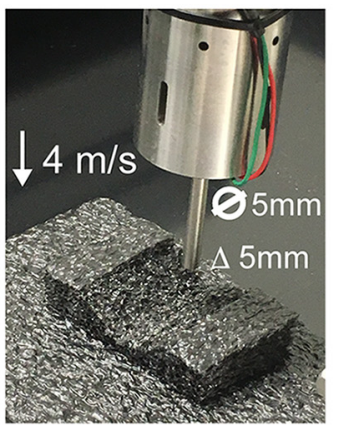

B

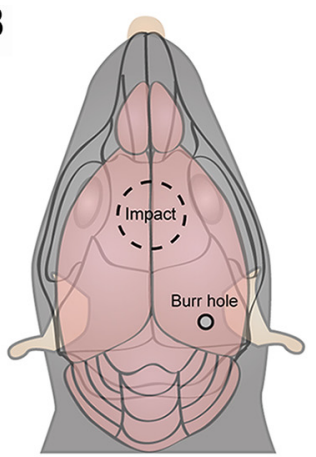

C
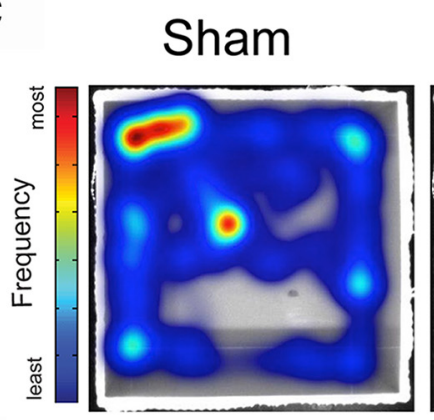

$4 \mathrm{~m} / \mathrm{s}$

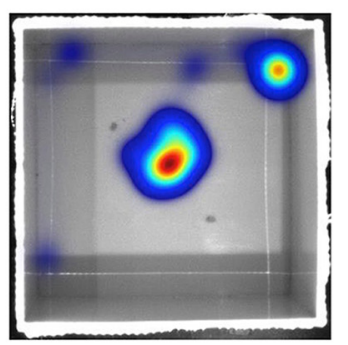

D
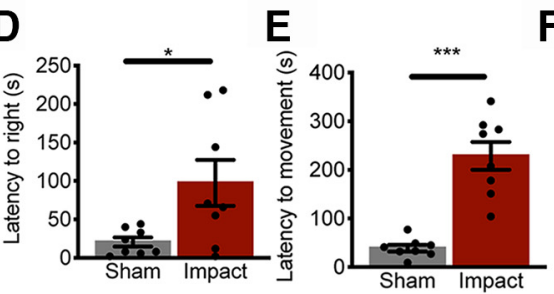

$\mathbf{F}$

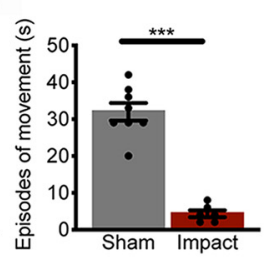

G
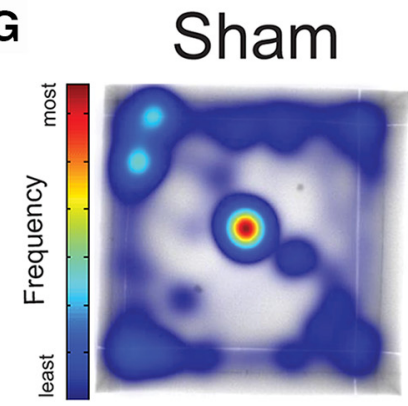

$2 \mathrm{~m} / \mathrm{s}$

H

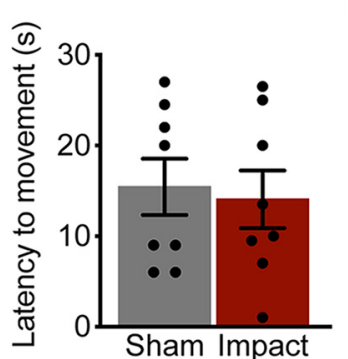

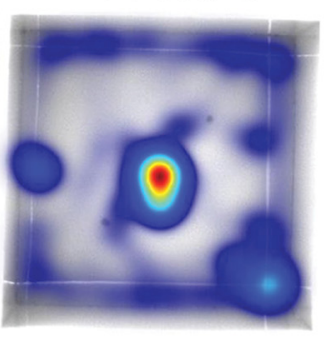

I

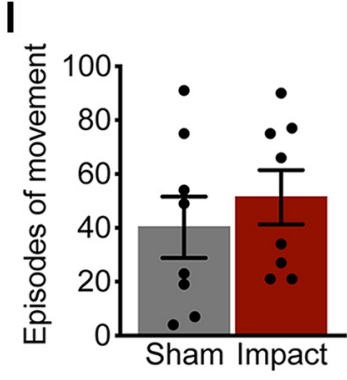

Figure 1. Closed skull impacts induce mTBI-like behavior. $\boldsymbol{A}$, Animals are anesthetized with isoflurane and placed on a custom Kaizen foam platform and impacted without restricting the head. Animals were impacted on top of the head at 2 or $4 \mathrm{~m} / \mathrm{s}$ with a 5-mm diameter and a 5-mm deflection. $\boldsymbol{B}$, Schematic representation of the impact site including the position of the burr hole for

Figure 1. continued

the electrophysiological recordings. $\boldsymbol{C}$, Representative heatmaps indicating positions most frequently visited in warmer colors. The impacted animals displayed a prolonged time in the center following the impact and did not explore the arena as the shamtreated animals during the entire 10-min trial. Cumulative data for the latency to right themselves $(\boldsymbol{D})$, latency to regain movement $(\boldsymbol{E})$, and total episodes of movements $(\boldsymbol{F})$ over the entire 10-min trial. Representative heatmaps for sham and 2-m/s impacted animals show similar time in the center and exploratory behavior $(G)$. There was no significant difference in the latency to regain movement $(\boldsymbol{H})$ and total episodes of movement $(\boldsymbol{I})$ between sham and $2-\mathrm{m} / \mathrm{s}$ animals.

The $5 \mathrm{~mm}$ impactor tip was positioned with the front edge of the impact tip aligned with the eyes resulting in the impact center at $\sim 1 \mathrm{~mm}$ rostral to bregma. A schematic representation of the impact site is show in Figure 1B. The impactor tip was lowered to press the animals head down to the surface of the platform before tip retraction. The impactor was then lowered an additional $5 \mathrm{~mm}$ for the deflection. The animals were impacted at a speed of 4 or $2 \mathrm{~m} / \mathrm{s}$ with a dwell time of $20 \mathrm{~ms}$. The impact resulted in the deflection of the animal's head away from the impact site. Sham-treated animals were anesthetized, placed on the platform, and the impactor tip was lowered to touch the animal's head.

\section{Behavior of $\mathbf{m T B}$}

Mice were anesthetized with 2-4\% isoflurane (Clipper Distribution Company) supplemented with oxygen at a flow rate of $1 \mathrm{~L} / \mathrm{min}$. Isoflurane anesthesia allowed rapid recovery from anesthesia to monitor short-term behavioral effects. Following an impact, the animals were immediately placed on their side in the center of an open field arena. This permitted tracking of recovery and behavior within seconds of the impact. Behavior was monitored for $10 \mathrm{~min}$ using the Ethovison motion tracking system (Noldus). The time to righting reflex and initial movement was manually assessed. Recovery of movement was considered to be the first full step of the animal. Total distance traveled and episodes of movement were automatically calculated by the Ethovision system. The parameters were set so that velocities above $4.5 \mathrm{~m} / \mathrm{s}$ were considered moving and velocities below $1.75 \mathrm{~m} / \mathrm{s}$ was considered not moving. Intermediate velocities were excluded from the analysis. Movement heatmaps were generated for each animal for a 10-min trial.

\section{Behavioral and cognitive tasks Home cage monitoring}

We used the photobeam activity system (PAS) (San Diego Instruments) to monitor behavior continuously for multiple days after the impact. Animals were singly housed with 1/4-inch corncob bedding $\sim 3 / 8$ of an inch deep under a normal light cycle. Animals were acclimated to the corncob bedding for $24 \mathrm{~h}$ before monitoring. Each cage was placed within the photobeam detectors and beam breaks were accumulated into 5 -min bins. Animals were monitored for $24 \mathrm{~h}$ before treatment. Animals were only removed from their cage for anesthesia and treat- 
ment (sham vs mTBI), and immediately placed back into their cage within $5 \mathrm{~s}$ of the impact. Animals were monitored for an additional $5 \mathrm{~d}$. Acute mobility was assessed for $4 \mathrm{~h}$ following treatment (5-min bins) and long-tern mobility was assessed for $7 \mathrm{~d}$, beginning $24 \mathrm{~h}$ before treatment (60-min bins).

\section{Open field and novel object recognition}

Open field behavior was monitored via the Ethovison motion tracking system $24 \mathrm{~h}$ after the impact to broadly assess mobility and anxiety. The arena was well lit with $\sim 300$ lux in the center of the arena and $\sim 200$ lux in the corners. Each animal was placed into the center of the arena and monitored for 10 min before returning back to its home cage. Total times spent in the center and border regions were calculated, as well as the total distance traveled. The novel object task was used to assess learning and memory $48 \mathrm{~h}$ after the impact. The open field setup was used with identical settings and two identical objects were placed at the opposite corners of the arena. The animals were allowed to explore the objects for $5 \mathrm{~min}$. The animals were removed from the arena and the two objects and the arena was wiped down. One identical object and one novel object were placed back into the arena. Within $5 \mathrm{~min}$, the mice were allowed to explore the two objects for $5 \mathrm{~min}$. The total duration of time spent investigating the identical and novel objects were quantified as a measure of learning and memory.

\section{CatWalk gait analysis}

We used the Noldus CatWalk system to quantify gait characteristics $72 \mathrm{~h}$ after the impact. Individual animals were placed on the glass platform and the animals were allowed to freely walk up and down the CatWalk. A camera from below captured the animal's footprint for automated analysis. The following parameters were used for a successful run: minimum duration of $0.5 \mathrm{~s}$, maximum duration of $10 \mathrm{~s}$, and during each run the animal's speed could not change $>65 \%$. Each run was classified and the following characteristics were analyzed to assess for gait abnormalities: print area, swing duration, and stride length. Print area was calculated by averaging the area of all the footprints for each individual paw. Swing duration was considered to be the time between the lifting and replacing of the same paw. The stride length was calculated by the distance from the heel of one footprint to the heel of the next footprint of the same paw.

\section{Trace fear conditioning}

We used fear conditioning boxes that were equipped with infrared motion tracking capabilities (Med Associates Inc). Animals were treated $24 \mathrm{~h}$ before fear conditioning. Animals were conditioned to the box $120 \mathrm{~s}$ before the first 30 -s tone that was followed by a 20-s delay and a 2-s foot shock at $0.6 \mathrm{~mA}$. This was repeated five times with an average inter-event interval of $120 \mathrm{~s}$. On day 2, the fear conditioning boxes were moved to a different location, the walls and floors were change, and a vanilla scent was added to the behavior box. Animals were again placed into the box, given the tone for $30 \mathrm{~s}$ with no foot shock. This was repeated three times with an inter-event interval of $220 \mathrm{~s}$. On day 3 , the behavior boxes were moved back to the previous location with the original walls and floors. The animals were place into the box for a total of $480 \mathrm{~s}$. The automated motion tracking capabilities of the behavior boxes was used to assess freezing and the percentage time freezing was calculated. Freezing was calculated for day 2 during the tone and delay period of 220-s delay. For day 3 , the entire $480 \mathrm{~s}$ was assessed for freezing behavior.

\section{Laser speckle contrast imaging (LSCl) and electrophysiological recordings}

Animals were anesthetized with $1.5 \mathrm{mg} / \mathrm{g}$ urethane (Sigma-Aldrich) before treatment and remained under anesthesia for the entirety of the experiment. Following the completion of the experiment the animals were sacrificed by decapitation. LSCI (Boas and Dunn, 2010; Miao et al., 2011) was used to monitor CBF through the intact skull. A skin flap was created to expose the skull and the skull was illuminated with a $785 \mathrm{~nm}$ laser diode (Thorlabs). The scattered light was collected through a $720 \mathrm{~nm}$ long pass filter and a Nikon 18- to 55-mm manual focus lens (f-stop between 3.5 and 5.6) attached to a stingray F-504 CCD camera (Allied Vision). Blood flow maps were calculated and displayed using LabView software (National Instruments) modified from Choi and colleagues (Yang et al., 2011). Normalized blood flow measurements were calculated from the $\mathrm{LSCl}$ images using ImageJ $(\mathrm{NIH})$. Blood flow was quantified by creating a $600 \times 600 \mu \mathrm{m}$ region of interest (ROI) over the visual cortex in either hemisphere. The averaged pixel intensity of that region was calculated and plotted over time to demonstrate the dynamic blood flow changes that are associated with SDs. For the reperfusion data set, 100 individual images were averaged together to represent each time point and a $600 \times 600 \mu \mathrm{m}$ $\mathrm{ROI}$ was again used over the visual cortex or major vessel. $\mathrm{ROI}$ placement was based on a consistent anatomic location throughout the repeated measurements. All data were normalized to pre-impact LSCI levels. Chronic windows were created to monitor CBF for multiple days following a single impact. An incision was generated over the right hemisphere above the visual cortex and the underlying skull was exposed and cleaned. A drop of cyanoacrylate glue was placed on the skull and a $4 \mathrm{~mm}$ diameter cover glass was placed on the glue and skull. The skin was securely glued to the underlying skull and cover glass. Animals were allowed to recover from the surgery for 24-48 $\mathrm{h}$ before treatment.

Electrophysiological recordings were done with an Axon 2B amplifier (Molecular Devices) equipped with a HS-2A headstage. Data were acquired at $10 \mathrm{kHz}$ using a PowerLab 8/35 (AD Instruments) acquisition system and LabChart 7. Glass electrodes were pulled with a P-97 Flaming/Brown Micropipette puller (Sutter Instruments) and filled with artificial CSF (ACSF) containing the following: $125 \mathrm{mM} \mathrm{NaCl}, 2 \mathrm{mM} \mathrm{KCl}, 1.3 \mathrm{mM} \mathrm{NaH}_{2} \mathrm{PO}_{4}, 26 \mathrm{mM}$ $\mathrm{NaCO}_{3}, 10 \mathrm{mM}$ glucose, $2 \mathrm{mM} \mathrm{CaCl}$, and $1 \mathrm{mM} \mathrm{MgSO}_{4}$. Electrodes were placed $\sim 500 \mu \mathrm{m}$ beneath the surface of the brain through a burr hole in the skull located over the visual cortex (Fig. 1B). The burr hole was generated 60 min before baseline recordings. To maintain the validity of 
the model, these recordings were done without head restriction resulting in some movement artifacts from animal respiration. Baseline electrophysiological data were acquired before the impact. The electrode was removed for the impact and then replaced within $5 \mathrm{~s}$. These recordings were done with simultaneous $\mathrm{LSCl}$ to ensure that SD was not generated from the insertion of the electrode. Electrophysiological recordings were quantified following the recommendations of the Co-Operative Study on Brain Injury Depolarizations (COSBID) group (Dreier et al., 2017). In brief, the slow extracellular potential shifts of SD were assessed after the low pass filter was set at $5 \mathrm{~Hz}$. SD onset was considered to occur at the initial drop of the DC shift and recovery was considered to be when the extracellular potential reached $85 \%$ of the pre-SD level. Highfrequency activity was monitored using a bandpass filter between 0.5 and $45 \mathrm{~Hz}$. Recovery of high-frequency activity was assessed from the total power of the highfrequency activity $\left(\mathrm{V}^{2}\right)$. As recommended, the first spike in the total power signal was considered recovery of the high-frequency activity.

Ketamine was used as a pharmacological blocker of SDs to confirm that the impact-induced SDs were sensitive to NMDA receptor antagonists. Ketamine was administered via an intraperitoneal injection 30-45 min before the impact at a dose of $120 \mathrm{mg} / \mathrm{kg}$ (Hernándéz-Cáceres et al., 1987; von Bornstädt et al., 2015). Due to the anesthetic actions of ketamine at this concentration, the urethane dosage was halved and the animals were monitored for a pain response. Ketamine was given 10 min before the urethane and the impact was given within $45 \mathrm{~min}$ of the ketamine injection.

\section{Histology and immunohistochemistry}

For histologic analysis the animals were sacrificed $24 \mathrm{~h}$ post-treatment. Animals were heavily anesthetized with isoflurane and were cardiac perfused first with ice-cold PBS containing 1 unit/mL heparin followed by ice-cold $4 \%$ paraformaldehyde (Sigma-Aldrich). Brains were removed and immediately submerged in $4 \%$ paraformaldehyde for $48 \mathrm{~h}$ at $4^{\circ} \mathrm{C}$. Brains were sectioned using a vibrating vibratome (VT1000S, Leica) at a thickness of 50 $\mu \mathrm{m}$. Sections were immediately placed in cryoprotection solution and maintained at $-20^{\circ} \mathrm{C}$.

For Nissl staining, sections were transferred to frosted slides and allowed to dry. Sections were then dehydrated with ethanol $(2 \times 3 \mathrm{~min})$ and cleared with xylene $(15 \mathrm{~min})$. Sections were washed in $100 \%$ ethanol $(2 \times 3 \mathrm{~min})$ and rinsed in tap water. Sections were stained for 4-8 $\mathrm{min}$ in $0.1 \%$ cresyl violet and rinsed with tap water then washed with $100 \%$ ethanol $(2 \times 3 \mathrm{~min})$ before mounting in Permount (catalog \#SP15, Fisher Chemical).

To assess for micro-bleeds or blood brain barrier disruptions we used a Prussian blue kit from Abcam (catalog \#ab150674). In brief, sections were mounted on charged slides and allow to fully dry. Sections were rehydrated in PBS two times for 5 min each. Slides were dipped into $\mathrm{diH}_{2} \mathrm{O}$ and placed into the iron stain for $5 \mathrm{~min}$. Slides were immediately transferred to a NucRed stain for $2 \mathrm{~min}$. Slides were washed four times in $\mathrm{diH}_{2} \mathrm{O}$ and dehydrated with $95 \%$ and $100 \%$ ethanol for 2 min each. Sections were cleared in xylene for 5 min and mounted with Permount.

The in situ apoptosis detection kit from Sigma-Aldrich (catalog \#S7100) was used to assess for cell death with TUNEL staining. Sections were mounted on charged slides and allowed to dry completely. Sections were rehydrated in PBS and the procedures from the kit were followed. DAB labeling was done with the ImmPACT DAB kit from Vector Laboratories (catalog \#SK-4105). Images were converted to 8-bit gray scale and converted to red for the representative images in ImageJ.

For immunohistochemical assessment, sections were washed in PBS-T and then blocked using 5\% normal donkey serum and $1 \%$ bovine serum albumin in PBS-T for $1 \mathrm{~h}$. To assess for cell death, sections were stained with Fluoro-Jade C solution (0.0001\% Fluoro-Jade C in 0.1\% acetic acid; catalog \#AG325, EMD Millipore Corp, Merk) for $10 \mathrm{~min}$. Sections were washed with PBS-T twice for 10 min each and mounted. Glial fibrillary acidic protein (GFAP) was used as a marker of astrocyte activation and the primary antibody (catalog \#NE1015, EMD Millipore, Merk) was diluted 1:500 in the blocking buffer and incubated at $4^{\circ} \mathrm{C}$ overnight. The following day, the sections were washed in PBS-T three times for 10 min each before being incubated with the secondary antibody [Cy3-IgG $(\mathrm{H}$ $+\mathrm{L})$ donkey anti-mouse, catalog \#715-167-003, Jackson ImmunoResearch] at room temperature for $2 \mathrm{~h}$. Sections were washed three times for 10 min each in PBS-T, then mounted onto slides. All images were acquired with an Olympus IX71 inverted microscope equipped with an Olympus DP72 RGB camera through either a $4 \times$ UPlanFL N 0.13 na objective, $10 \times$ UPlanFI 0.3 na objective, or $40 \times$ LUCPlanFLN 0.60 na objective. Images were acquired and stitched with the Olympus cellSens software system and quantified with ImageJ.

\section{Statistical analysis}

All statistical analyses were performed in Prism (v.8). All datasets were tested for a normal distribution using the D'Agostino-Pearson test, and for outliers using the Rout test with $Q=1 \%$. All statistical analyses of pooled data were performed using a two-tailed Student's $t$ test or Mann-Whitney tests, and the level of significance was considered to be $p<0.05$. All statistics are provided in the figure legends and data are presented as group means and SEMs. For details of results of statistical analyses, see Table 1.

\section{Results}

\section{Closed skull impact results in acute mTBI-like behavior}

We used video monitoring to investigate post-mTBI behavior. Animals were anesthetized with isoflurane and placed on a custom-made foam platform. The platform supported the head in a horizontal position, but did not restrict the head or body (Fig. 1A). The platform and impactor are shown in Figure $1 A$. A schematic representation of the impact site is shown in Figure 1B. Immedi- 
Table 1. Statistics table

\begin{tabular}{|c|c|c|c|c|c|c|}
\hline Description & Figure & $\begin{array}{c}\text { Normal } \\
\text { distribution }\end{array}$ & Method & Significant & $t$ or $F$ & $p$ value \\
\hline $4-\mathrm{m} / \mathrm{s}$ latency to right & $1 D$ & Yes & $D^{\prime}$ Agostino-Pearson and $\mathrm{S}-\mathrm{W}$ & Yes & $t=2.530$ & $p=0.024$ \\
\hline $4-\mathrm{m} / \mathrm{s}$ latency to movement & $1 E$ & Yes & $D^{\prime}$ Agostino-Pearson and $S-W$ & Yes & $t=6.413$ & $p<0.0001$ \\
\hline $4-\mathrm{m} / \mathrm{s}$ episodes of movement & $1 F$ & Yes & $D^{\prime}$ Agostino-Pearson and $\mathrm{S}-\mathrm{W}$ & Yes & $t=9.46$ & $p<0.0001$ \\
\hline $2-\mathrm{m} / \mathrm{s}$ latency to movement & $1 H$ & Yes & $\mathrm{D}^{\prime}$ Agostino-Pearson and $\mathrm{S}-\mathrm{W}$ & No & $t=0.309$ & $p=0.7618$ \\
\hline $2-\mathrm{m} / \mathrm{s}$ episodes of movement & $1 I$ & Yes & $\mathrm{D}^{\prime}$ Agostino-Pearson and $\mathrm{S}-\mathrm{W}$ & No & $t=0.7336$ & $p=0.4753$ \\
\hline 4-h home cage monitoring & $2 A$ & No & $D^{\prime}$ Agostino-Pearson and $S-W$ & No & $F=0.0806$ & $p=0.781$ \\
\hline $5-\mathrm{d}$ home cage monitoring & $2 B$ & No & $D^{\prime}$ Agostino-Pearson and $S-W$ & No & $F=0.7883$ & $p=0.3747$ \\
\hline 24-h open field total dis & $2 C$ & Yes & $D^{\prime}$ Agostino-Pearson and $S-W$ & No & $t=1.051$ & $p=0.311$ \\
\hline 24-h open field center & $2 D$ & No & $\mathrm{D}^{\prime}$ Agostino-Pearson and $\mathrm{S}-\mathrm{W}$ & No & $\mathrm{M}-\mathrm{W}$ & $p=0.2345$ \\
\hline 24-h open field borders & $2 E$ & No & $\mathrm{D}^{\prime}$ Agostino-Pearson and $\mathrm{S}-\mathrm{W}$ & No & $\mathrm{M}-\mathrm{W}$ & $p=0.2786$ \\
\hline $48-\mathrm{h}$ NOR & $2 F$ & Yes & $\mathrm{D}^{\prime}$ Agostino-Pearson and $\mathrm{S}-\mathrm{W}$ & Yes & $F=5.741$ & $p=0.0235$ \\
\hline 72-h CatWalk print area $R F$ & $2 G$ & Yes & $D^{\prime}$ Agostino-Pearson and $\mathrm{S}-\mathrm{W}$ & No & $t=0.8259$ & $p=0.4284$ \\
\hline 72-h CatWalk print area $\mathrm{RH}$ & $2 G$ & Yes & $D^{\prime}$ Agostino-Pearson and $\mathrm{S}-\mathrm{W}$ & No & $t=0.552$ & $p=0.5897$ \\
\hline 72-h Catwalk print area LF & $2 G$ & Yes & $\mathrm{D}^{\prime}$ Agostino-Pearson and $\mathrm{S}-\mathrm{W}$ & No & $t=0.0714$ & $p=0.9441$ \\
\hline 72-h CatWalk print area LH & $2 G$ & Yes & $D^{\prime}$ Agostino-Pearson and $S-W$ & No & $t=0.3652$ & $p=0.7204$ \\
\hline 72-h Catwalk swing duration RF & $2 H$ & Yes & $D^{\prime}$ Agostino-Pearson and $S-W$ & No & $t=0.5281$ & $p=0.5950$ \\
\hline 72-h Catwalk swing duration $\mathrm{RH}$ & $2 H$ & No & $D^{\prime}$ Agostino-Pearson and $S-W$ & Yes & $\mathrm{M}-\mathrm{W}$ & $p=0.0379$ \\
\hline 72-h Catwalk swing duration LF & $2 H$ & Yes & $\mathrm{D}^{\prime}$ Agostino-Pearson and $\mathrm{S}-\mathrm{W}$ & No & $t=1.228$ & $p=0.2398$ \\
\hline 72-h Catwalk swing duration $\mathrm{LH}$ & $2 H$ & Yes & $\mathrm{S}-\mathrm{W}$ only & No & $t=0.1183$ & $p=0.9076$ \\
\hline 72-h CatWalk stride length RF & $2 I$ & Yes & $\mathrm{D}^{\prime}$ Agostino-Pearson and $\mathrm{S}-\mathrm{W}$ & No & $t=0.9193$ & $p=0.3735$ \\
\hline 72-h CatWalk stride length RH & $2 I$ & Yes & $\mathrm{D}^{\prime}$ Agostino-Pearson and $\mathrm{S}-\mathrm{W}$ & No & $t=1.249$ & $p=0.2321$ \\
\hline 72-h CatWalk stride length LF & $2 I$ & Yes & $D^{\prime}$ Agostino-Pearson and $S-W$ & No & $t=0.7567$ & $p=0.4618$ \\
\hline 72-h CatWalk stride length LH & $2 I$ & Yes & $D^{\prime}$ Agostino-Pearson and $S-W$ & No & $t=0.7110$ & $p=0.8666$ \\
\hline GFAP quantification & $3 E$ & Yes & D'Agostino-Pearson only & No & $t=1.295$ & $p=0.2138$ \\
\hline FluroJade quantification & $3 F$ & Yes & $D^{\prime}$ Agostino-Pearson and $S-W$ & No & $t=0.8128$ & $p=0.4282$ \\
\hline \multirow[t]{11}{*}{ Prolonged CBF recovery tissue } & $5 B$ overall & Yes & $\mathrm{D}^{\prime}$ Agostino-Pearson and $\mathrm{S}-\mathrm{W}$ & & & \\
\hline & $5 B 0 \mathrm{~min}$ & & & No & & $p>0.9999$ \\
\hline & $5 B 5 \mathrm{~min}$ & & & No & & $p>0.9999$ \\
\hline & $5 B 15 \mathrm{~min}$ & & & Yes & & $p=0.0033$ \\
\hline & $5 B 30 \mathrm{~min}$ & & & Yes & & $p=0028$ \\
\hline & $5 B 45 \mathrm{~min}$ & & & Yes & & $p=0.0001$ \\
\hline & $5 B 60 \mathrm{~min}$ & & & Yes & & $p=0.0014$ \\
\hline & $5 B 75 \mathrm{~min}$ & & & No & & $p=0.2927$ \\
\hline & $5 B 90 \mathrm{~min}$ & & & No & & $p>0.9999$ \\
\hline & $5 B 105 \mathrm{~min}$ & & & No & & $p>0.9999$ \\
\hline & $5 B 120 \mathrm{~min}$ & & & No & & $p>0.9999$ \\
\hline \multirow[t]{11}{*}{ Prolonged CBF recovery venous } & $5 \mathrm{C}$ overall & Yes & $\mathrm{D}^{\prime}$ Agostino-Pearson and $\mathrm{S}-\mathrm{W}$ & No & & $p>0.9999$ \\
\hline & $5 \mathrm{C} 0 \mathrm{~min}$ & & & No & & $p>0.9999$ \\
\hline & $5 C 5 \mathrm{~min}$ & & & Yes & & $p=0.0272$ \\
\hline & $5 C 15 \min$ & & & Yes & & $p=0.0016$ \\
\hline & $5 \mathrm{C} 30 \mathrm{~min}$ & & & Yes & & $p=0.0103$ \\
\hline & $5 C 45 \mathrm{~min}$ & & & Yes & & $p=0010$ \\
\hline & $5 C 60 \mathrm{~min}$ & & & Yes & & $p=0.0302$ \\
\hline & $5 C 75 \mathrm{~min}$ & & & No & & $p=0.6456$ \\
\hline & $5 C 90 \mathrm{~min}$ & & & No & & $p>0.9999$ \\
\hline & $5 C 105 \mathrm{~min}$ & & & No & & $p>0.9999$ \\
\hline & $5 C 120 \mathrm{~min}$ & & & No & & $p>0.9999$ \\
\hline \multirow[t]{6}{*}{ Multi-day CBF recovery } & $5 F$ & No & $\mathrm{S}-\mathrm{W}$ only & & & \\
\hline & & & & & & $p>0.9999$ \\
\hline & & & & & & $p<0.0001$ \\
\hline & & & & & & $p=0.5034$ \\
\hline & & & & & & $p=0.4908$ \\
\hline & & & & & & $p=0.9819$ \\
\hline SD occurance Ure vs Iso & $5 G$ & Yes & $D^{\prime}$ Agostino-Pearson and $\mathrm{S}-\mathrm{W}$ & No & $t=0.00902$ & $p=0.9929$ \\
\hline
\end{tabular}

ately following treatment, animals were placed in the center of an open field arena and monitored for $10 \mathrm{~min}$. On average the mTBI animals righted themselves in 97.5 $\mathrm{s}$ compared to $20.6 \mathrm{~s}$ for the sham-treated animals $\left(t_{(14)}=\right.$ 2.53, $p=0.02$; sham $n=8$; mTBI $n=9$; Fig. $1 D$ ). Representative heat maps are shown in Figure $1 C$ to demonstrate the overall difference between the treatment groups. In addition to the righting reflex, the $\mathrm{mTBI}$ animals took on average $228.7 \mathrm{~s}$ to regain movement versus 39.1 $s$ for the sham animals $\left(t_{(14)}=6.413, p<0.0001\right.$; Fig. $\left.1 E\right)$. Following the recovery of movement, the mTBI animals averaged 4.3 episodes of movement whereas the sham- treated animals averaged 32 episodes $\left(t_{(12)}=9.46, p<\right.$ 0.0001 ; Fig. $1 F$. This behavior resembled the acute disorientation symptoms of human $\mathrm{mTBI}$, and led us to ask if this behavior was dependent on the severity of the impact. In a separate cohort, animals were impacted at 2 $\mathrm{m} / \mathrm{s}$ instead of $4 \mathrm{~m} / \mathrm{s}$ with all the other parameters maintained. Animals that were impacted at $2 \mathrm{~m} / \mathrm{s}$ did not display the initial period of immobility (sham $=15.4 \mathrm{~s}$ vs 2 $\mathrm{m} / \mathrm{s}=14.06 \mathrm{~s} ; t_{(14)}=0.31, p=0.762$; Fig. $\left.1 H\right)$ and had similar episodes of movement (sham $=40.2 \mathrm{vs} 2 \mathrm{~m} / \mathrm{s}=$ 51.3; $t_{(14)}=0.734, p=0.475$; sham $n=8 ; 2 \mathrm{~m} / \mathrm{s}$ impact $n=8$; Fig. 1/). Representative heat maps indicate similar 
patterns movement between groups in the acute behavior following a 2-m/s impact (Fig. 1G).

\section{A single $\mathrm{mTBI}$ does not result in significant deficits in long-term behavior, gait, or learning and memory}

To assess behavior on a longer time scale we used a home cage photobeam system to monitor animal movement continuously for multiple hours and days. We were able to confirm our previous open field studies, by showing that the mTBI group had on average 2.5 beam breaks in the first 5 min compared to 15.2 in the sham treated (Fig. 2A). The $\mathrm{mTBI}$ animals were more active $1 \mathrm{~h}$ after the impact relative to the sham-treated animals, but post hoc analysis did not show any statistically significantly difference between the groups $\left(F_{(1,14)}=0.081, p=0.781\right.$; Fig. $2 A$; Table 1). Furthermore, the active and sleep cycles were nearly identical in both treatment groups for five consecutive days $\left(F_{(1,2016)}=0.788, p=0.375\right.$; Fig. $2 B$; Table 1). In a separate cohort of animals, we tested for activity and general anxiety using the open field task $24 \mathrm{~h}$ post-treatment. There was no statistical difference between the sham or mTBI animals in total distance traveled $\left(t_{(14)}=1.051, p=0.311\right)$, in the duration spent in either the center $\left(t_{(14)}=0.704, p=0.493\right)$, or duration in the border regions $\left(t_{(14)}=0.704, p=0.493\right.$; Fig. $\left.2 C-E\right)$. To test for learning and memory we used the novel object recognition task $48 \mathrm{~h}$ post-treatment. Both treatment groups investigated the novel object significantly more than the familiar object $\left(F_{(1,28)}=5.741, p=0.023\right)$ and there was no statistical difference between treatment groups $\left(F_{(1,28)}\right.$ $=0.0001, p=0.991$; Fig. $2 F)$. One common deficit among $\mathrm{mTBI}$ models is the presence of gait abnormalities. To test for gait abnormalities $72 \mathrm{~h}$ post-treatment, we used the CatWalk automated system. We investigated the footprint area, swing duration, and stride length (Fig. 2G-I), which have been previously been shown to have deficits in a similar mTBI model (Mountney et al., 2017; Neumann et al., 2009). We were unable to detect any significant differences between the sham and mTBI animals (Table 1). In another cohort, we used the contextual fearbased task as a more sensitive measure for learning and memory. Animals were conditioned to the tone $24 \mathrm{~h}$ post$\mathrm{mTBI}$ and then tested $24 \mathrm{~h}$ post-conditioning for freezing behavior in a different context. Animals were placed in a modified cage and given the associated tone with no foot shock. Both treatment groups had equivalent freezing during the tone $\left(t_{(14)}=0.095, p=0.925\right.$; Fig. $\left.2 G\right)$ and the delay period $\left(t_{(14)}=0.688, p=0.502\right.$; Fig. $\left.2 H\right)$. Twentyfour hours later, the animals were placed in the original context and total freezing was assessed. There was no statistical difference between the treatment groups in the total degree of freezing $\left(t_{(14)}=1.523, p=0.151\right.$; Fig. $\left.2 /\right)$. Together, these data suggest that the mTBls do not result in long-term deficits in mobility, sleep wake cycles, gait, or learning and memory.

\section{mTBI model does not produce significant tissue damage or astrocyte activation}

Histologic and immunohistochemical analyses were used to determine whether our $\mathrm{mTBI}$ model resulted in tissue damage and/or astrocyte activation. Previous stud- ies have shown pathologic damage $24 \mathrm{~h}$ post-mTBI (McAteer et al., 2016; Tagge et al., 2018). Therefore, we sacrificed and perfused sham and mTBI animals $24 \mathrm{~h}$ post-treatment. To assess for gross tissue damage, we used Nissl staining to label the rough endoplasmic reticulum of all cells. We were unable to detect any significant gross tissue damage directly beneath the impactor (striatal section) or in more caudal sections (hippocampal sections) located on the perimeter of the impact zone in either the $2 \mathrm{~m} / \mathrm{s}$ (sham $n=8$; impacted $n=8$; Fig. $3 A$ ) or $4 \mathrm{~m} / \mathrm{s}$ (sham $n=8, \mathrm{mTBI} n=8$; Fig. $3 B$ ) animals. We also used Prussian Blue staining to assess microbleeds and TUNEL staining to identify possible activated cell death. We used three to four sections that were physically separated (rostral to caudal) by $\sim 1-2 \mathrm{~mm}$ to span the entire brain. Microbleeds were very rare, with only two microbleeds in two separate animals observed. No microbleeds were observed in the other 18 sections from the remaining six mTBI animals, or from sham-treated animals (Fig. $3 C$ ). Likewise, TUNEL-positive neurons were extremely rare, with significant cell death being observed in only one of our mTBI animals (Fig. 3D). To more broadly test for cell death, we used FluoroJade-C staining in sham and $\mathrm{mTB}$ ( $4 \mathrm{~m} / \mathrm{s}$ ) animals. We were unable to find a significant difference in the FluoroJade fluorescence between sham and $\mathrm{mTBI}$ animals $\left(t_{(16)}=0.812, p=0.428\right.$; Fig. 3E,G; sham $n=8 ; \operatorname{mTBI} n=8)$. However, it is worth noting that the animal that did show positive TUNEL staining did have higher fluorescence in the FluoroJade-C stain. Another common feature of injury is neuroinflammation denoted by an increase in the expression levels of GFAP in astrocytes (Jones and Jarvis, 2017; Mountney et al., 2017). To assess this in our model we stained for GFAP $24 \mathrm{~h}$ postmTBI. Representative images are shown in Figure 3F. We normalized the fluorescence intensity within the medial corpus collosum to that of the lateral somatosensory cortex in sham and mTBI animals. Again, we were unable to detect a difference in GFAP fluorescence $\left(t_{(16)}=1.295\right.$, $p=0.214$; sham $n=8$; mTBI $n=8$; Fig. $3 H$ ). Due to the lack of histologic evidence of significant injury in the mTBI (i.e., $4 \mathrm{~m} / \mathrm{s}$ ) animals we did not extensively investigate damage in the $2-\mathrm{m} / \mathrm{s}$ impacted animals.

\section{mTBI impacts initiate SDs}

To investigate the presence of SDs in mTBls, we used LSCI and electrophysiology to monitor the CBF and the electrophysiological characteristics of SDs. A skin flap was generated to allow for LSCI but was placed over the skull during the impact. The skin flap did not negatively influence the impact, and the head deflected away from the impact, similar to impacts observed with the skin intact.

To monitor for hemodynamic responses associated with SDs we used LSCI. Following the sham or impact treatment the animal was immediately placed beneath the LSCI system within $\sim 3-5 \mathrm{~s}$. In sham-treated animals ( $n=$ 11) the CBF remained consistent throughout the cortical surface during the $5 \mathrm{~min}$ of imaging (Fig. $4 A, B$ ). However, animals that received a $4 \mathrm{~m} / \mathrm{s}$ impact displayed a propagating wave of hypoperfusion that slowly spread through- 
A

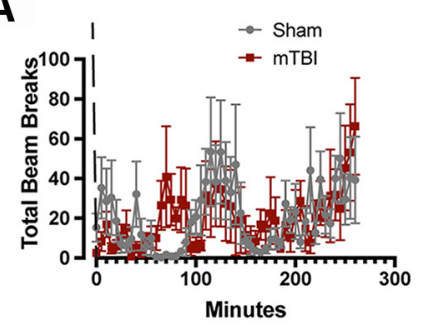

C

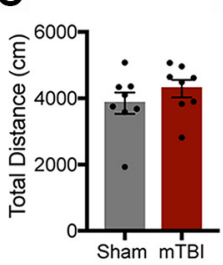

G

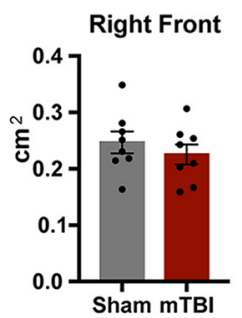

H

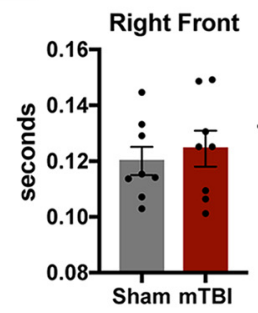

I

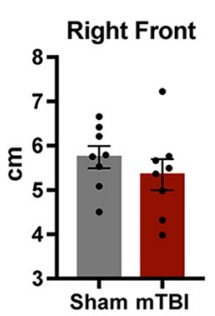

J
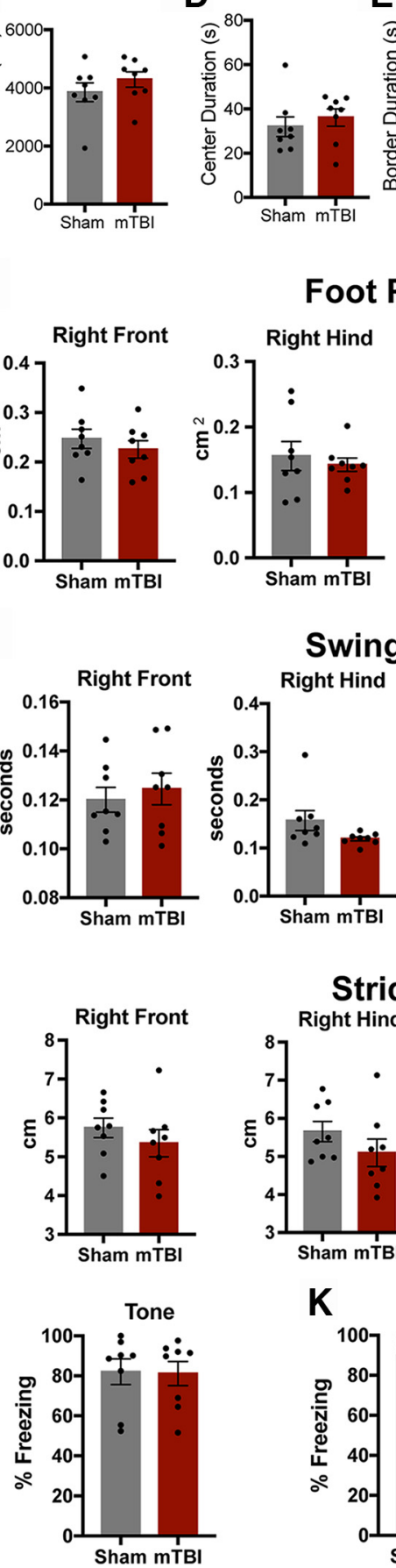

B

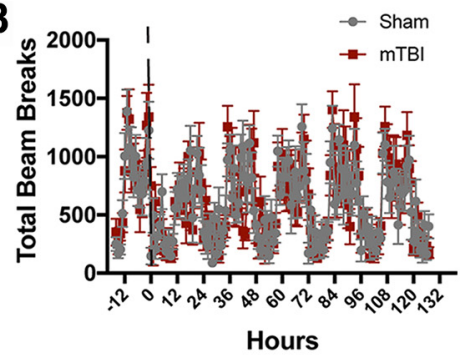

F

E

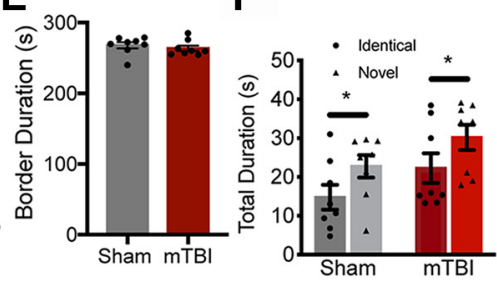

Foot Print Area
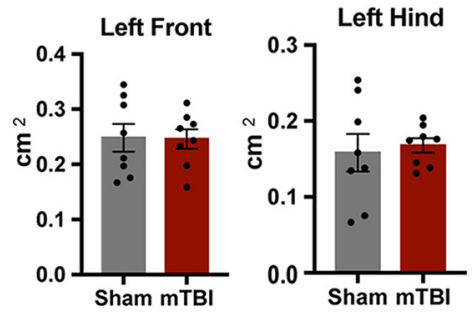

\section{Swing Duration}
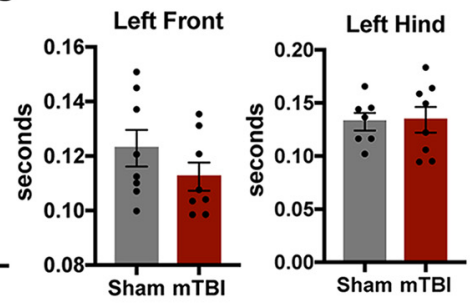

\section{Stride Length}
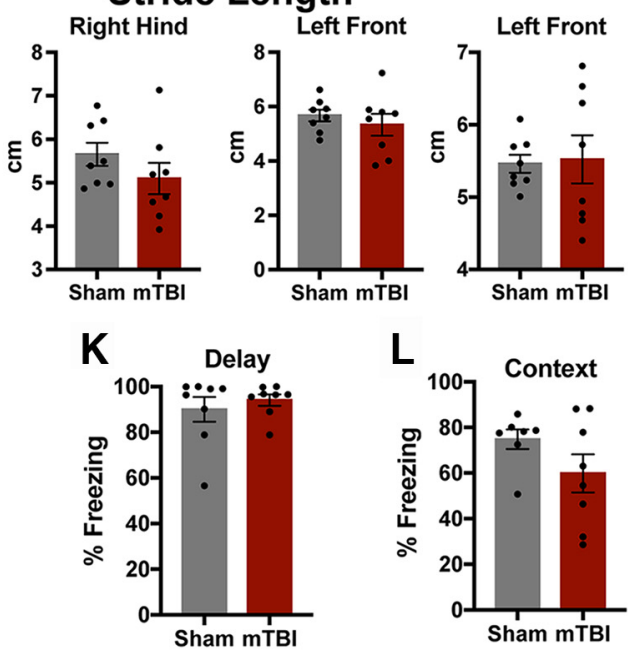

Figure 2. mTBls do not produce long-term deficits in ambulatory activity, gait, or learning and memory. Ambulatory activity was assessed with a photobeam home cage monitoring system immediately following the $4-\mathrm{m} / \mathrm{s}$ impact for $5 \mathrm{~d}$ continuously. Activity was assessed for $4 \mathrm{~h}$ immediately after the treatment in 5-min bins (A). To assess sleep wake cycles, the activity was monitored $24 \mathrm{~h}$ before 


\section{continued}

treatment and continuously for $6 \mathrm{~d}$ in 1-h bins $(\boldsymbol{B})$. The dashed line indicates the time of treatment (sham vs impact). Open field behavior was assessed $24 \mathrm{~h}$ post-sham or mTBI $(4 \mathrm{~m} / \mathrm{s})$ treatment to test for overall activity and anxiety. There was no significant difference in total distance traveled $(\boldsymbol{C})$, time spent in the center $(\boldsymbol{D})$, and time spent in the border regions $(\boldsymbol{E})$. Novel object recognition was used to test for short-term learning and memory $48 \mathrm{~h}$ post-treatment. Animals were placed into the open field arena containing two objects and allowed to explore the objects for $5 \mathrm{~min}$. Animals were removed and the arena, objects were cleaned, one identical object and one novel object were placed back into the arena, and the same animals was allowed to explore the objects for another $5 \mathrm{~min}$. The time spent with each object was quantified $(\boldsymbol{F})$. Using the Noldus CatWalk gait analysis system we quantified the footprint area $(\mathbf{G})$, swing duration $(\boldsymbol{H})$, and stride length $(\boldsymbol{I})$ for each individual foot $72 \mathrm{~h}$ post-treatment. Contextual trace fear conditioning was also used to assess for hippocampal dysfunction. $24 \mathrm{~h}$ post-treatment animals were placed within the behavioral box and given a $30-\mathrm{s}$ tone followed by a 20-s delay and a 0.6-mA foot shock for $2 \mathrm{~s}$. This was repeated five times to learn the association. On day 2 , the animals were put into a modified chamber and given the 30 -s tone without the foot shock. Freezing was assessed during the $30-\mathrm{s}$ tone $(\boldsymbol{J})$ and the 20-s delay $(\boldsymbol{K})$. On day 3 , the animals were placed into the original context for 8 min. The percentage of the time freezing during that 8 -min trial was quantified $(\boldsymbol{L})$.

out the cortical surface. Representative images and corresponding ROls are shown in Figure 4C, $D$ (mTBI $n=$ 12). The propagating waves of hypoperfusion have long been associated with SDs in mice (Tschirgi et al., 1957; Hansen et al., 1980; Paschen, 1984). The propagating wave of hypoperfusion (Phase I) was quickly followed by a brief increase in CBF (Phase II) that was then followed by a further reduction of $\mathrm{CBF}$ that resulted in longer term post-SD oligemia (Phase III). All of these phases are high- lighted in the CBF trace (Fig. 4D). We further tested whether the slower impacts at $2 \mathrm{~m} / \mathrm{s}$ produced similar propagating waves of hypoperfusion that are associated with SDs. Animals that were impacted at $2 \mathrm{~m} / \mathrm{s}$ had a stable CBF with no indications of a propagating wave (2 $\mathrm{m} / \mathrm{s} n=4$; Fig. 4E,F). Using the LSCl data we were able to calculate the propagation rate of the SDs by defining the wave front position over time. The impact induced SDs on average propagated at $3.5 \mathrm{~mm} / \mathrm{min}$ (Fig. $4 M$ ),
A

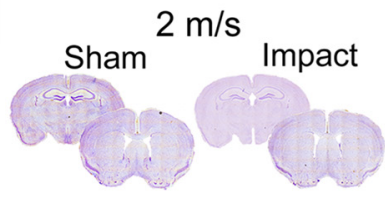

B
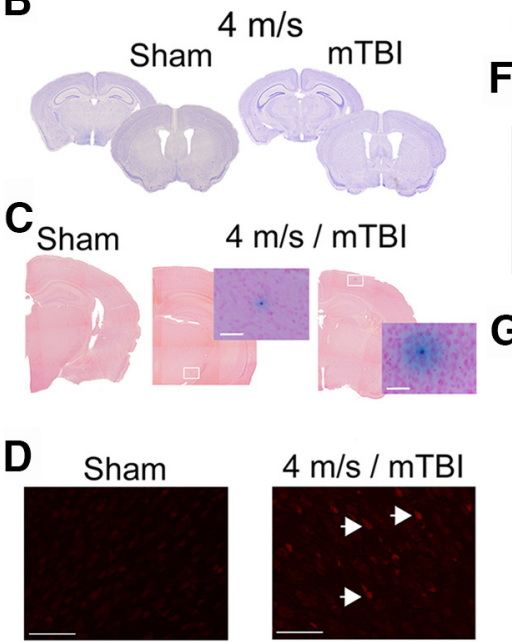

E
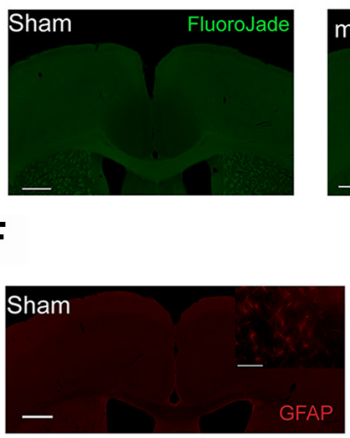

G

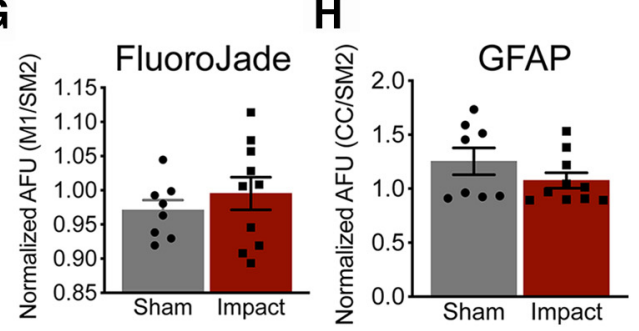

Figure 3. Impacts at $4 \mathrm{~m} / \mathrm{s}(\mathrm{mTBI})$ do not produce significant tissue damage or astrocyte activation. Representative Nissl stains indicating no gross structural damage $24 \mathrm{~h}$ post-impact for $2 \mathrm{~m} / \mathrm{s}(\boldsymbol{A})$ or $4 \mathrm{~m} / \mathrm{s}(\boldsymbol{B})$. Prussian blue stain was used to identify microbleeds and the tissue was counter stained with NucRed. Three to four sections per animal were stained, and we only identified the two microbleeds shown in $\mathbf{C}$ from two separate mTBI animals. No other microbleeds were present in the sham or the other six mTBI animals. Representative images for sham-treated animals and the two microbleed sections taken at $4 \times$ and $40 \times$ magnification images of the microbleed themselves $(\boldsymbol{C})$. The TUNEL stain was used to identify cells undergoing programed cell death. We only identified one $\mathrm{mTBI}$ animal that had detectable staining. Representative images are shown for sham-treated animals and the one mTB animal that had TUNEL-positive cells shown by the arrow heads $(\boldsymbol{D})$. Cell death was also assessed using FluoroJade-C. We were unable to detect a difference in overall fluorescent or individual cell bodies with positive staining. Representative images are shown $(\boldsymbol{E})$. Neuroinflammation was assessed by GFAP staining. Representative images are shown $(\boldsymbol{F})$. Again, we were unable to detect a difference in the overall fluorescence between the sham or $\mathrm{mTBI}(4 \mathrm{~m} / \mathrm{s})$ animals. Quantified fluorescence was measured by averaging the pixel intensity of the dorsal motor cortex to the lateral somatosensory cortex for sham and mTBI animals for FluoroJade (G) and GFAP staining $(\boldsymbol{H})$. Scale bars $=500 \mu \mathrm{m}$ (for the overview images) and $50 \mu \mathrm{m}$ (for the increased magnification). 
A

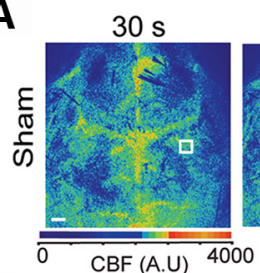

C

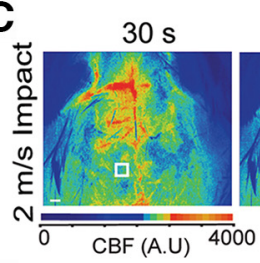

E

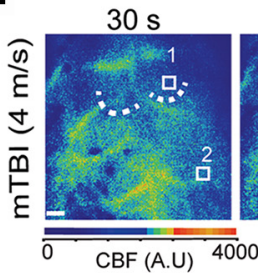

$50 \mathrm{~s}$

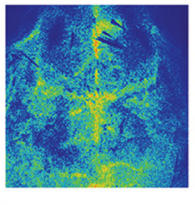

$50 \mathrm{~s}$

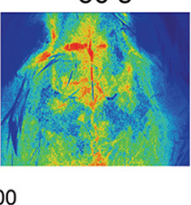

$50 \mathrm{~s}$
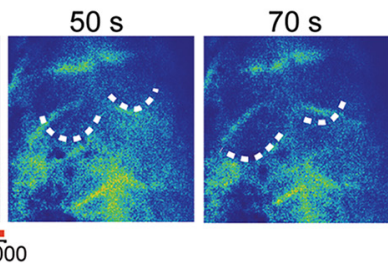

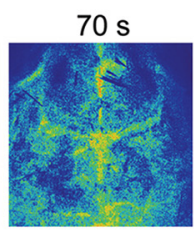

$70 \mathrm{~s}$
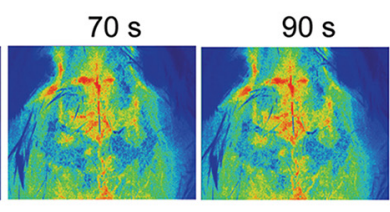

$90 \mathrm{~s}$

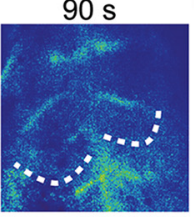

B

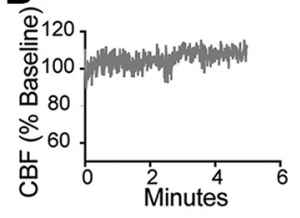

D

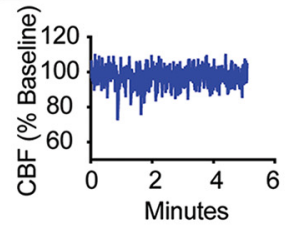

F

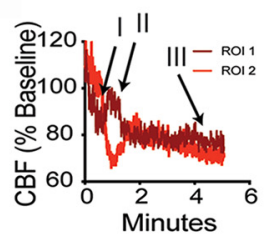

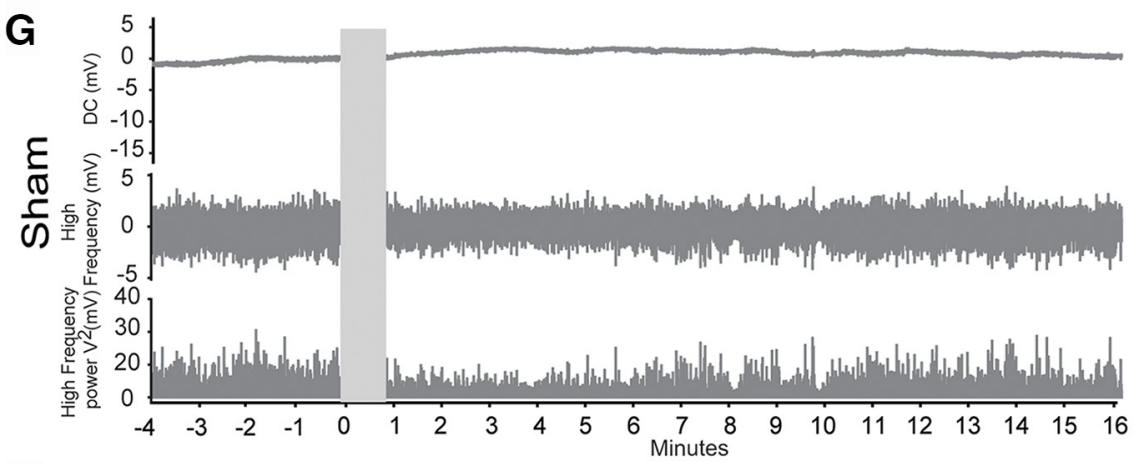
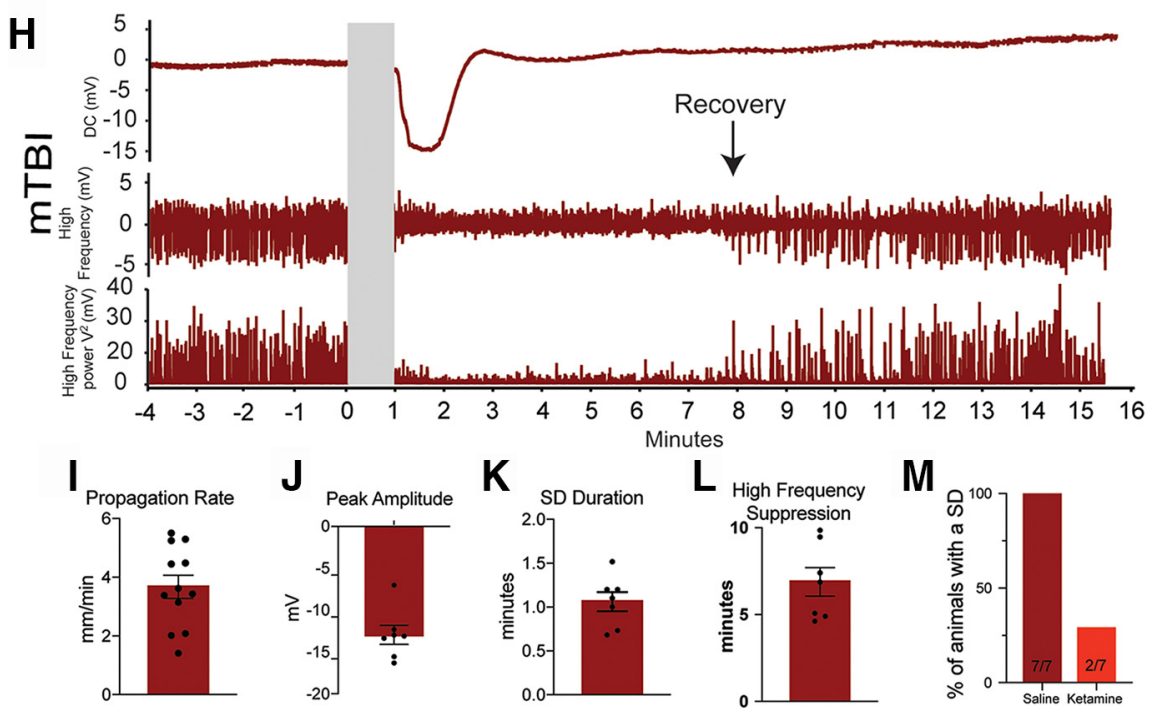

$\mathbf{L}$ High Frequency

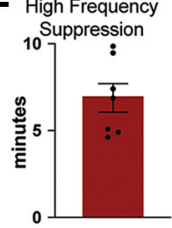

M

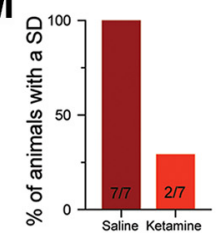

Figure 4. Impacts associated with mTBI-like behavior produce SD. LSCI was used to assess CBF before and immediately after treatment. Representative LSCl images from a sham $(\boldsymbol{A}), 2 \mathrm{~m} / \mathrm{s}(\boldsymbol{C})$, and $\mathrm{mTBI}(4 \mathrm{~m} / \mathrm{s} ; \boldsymbol{E})$ animals are shown. Warmer colors indicate more blood flow and the white boxes indicate the ROls used to create the time plots. Scale bars $=500 \mu \mathrm{m}$ (in the LSCI images). Dotted lines indicate the leading edge of the propagation wave. Graphical representations of the CBF from the indicated ROls are shown for sham $(\boldsymbol{B}), 2 \mathrm{~m} / \mathrm{s}(\boldsymbol{D})$, and mTBI $(\boldsymbol{F})$ animals. The two ROls from the $\mathrm{mTBI}$ animals indicate the propagation of the hemodynamic response. Representative electrophysiological recordings of the extracellular field potential, high-frequency activity, 


\section{continued}

and the total power $\left(\mathrm{V}^{2}\right)$ of the high frequency from a sham $(\boldsymbol{G})$ and mTBI animal $(\boldsymbol{H})$. Cumulative data of the propagation rate $(\boldsymbol{I})$, the SD extracellular field potential DC shift peak amplitude $(\boldsymbol{J})$ and duration $(\boldsymbol{K})$, and the duration of high-frequency suppression $(\boldsymbol{L})$. Ketamine (120 mg/kg) was given systemically 30-min before impact and the presence of an SD was assessed using LSCI ( $M$ ).

which is well within the published range of $2-6 \mathrm{~mm} / \mathrm{min}$ across tissue and species (Gorelova and Bures, 1983; Guedes and Barreto, 1992; Martin et al., 1994; Aitken et al., 1998; Oliveira-Ferreira et al., 2010; Santos et al., 2016).

To confirm the presence of a SD we used electrophysiological recordings in sham and $\mathrm{mTBI}$ animals. Immediately following an impact, a glass electrode was inserted through a burr hole located over the visual cortex within 5 $s$ of the impact (burr hole location shown in Fig. 1B). LSCI was simultaneously used to confirm that the electrode placement did not generate a SD. We were able to directly record the extracellular field potential shift and the suppression of high-frequency cortical activity, both of which are considered to be the gold-standard identifiers of SDs (mTBI $n=6$; Fig. 4H). In sham-treated animals, we did not detect any shift in extracellular potential or suppression of high-frequency activity (Fig. 4G). The average peak amplitude of the SDs was $12.97 \mathrm{mV}$ (Fig. 4I) with a duration of $1.06 \mathrm{~min}$ (Fig. 4J). These data are consistent with previously published properties of SDs evoked by other methods (i.e., $\mathrm{KCl}$, application, or electrical stimulation) in C57/B6 mice (Takano et al., 2007; von Baumgarten et al., 2008; Lindquist and Shuttleworth, 2014, 2017; Enger et al., 2015; Ebine et al., 2016; Chen et al., 2017; Kucharz and Lauritzen, 2018). To measure the duration of suppression of the high-frequency activity, we plotted the total power $\left(\mathrm{V}^{2}\right)$ of the high-frequency activity (Fig. 4G,H; Dreier et al., 2017). Recovery of the high frequency was considered to be the first spike in the total power above background (Dreier et al., 2017). The impact-induced SD resulted in an average of $6.88 \mathrm{~min}$ of high-frequency suppression (Fig. 4K).

Overall, we impacted 22 animals for these studies; 12 animals in our LSCI experiments (eight animals for the reperfusion and four animals for the multi-day recovery) and 10 animals in our electrophysiological studies. Of the 22 animals, SDs were detected in 18 animals ( $~ 82 \%)$. Interestingly, the four animals that did not display a SD were all in the electrophysiology group. We did not monitor for SDs during the burr hole surgery required for electrophysiological recordings, and it is possible that a SD or other damage was introduced before the impact and impaired the ability to generate an SD with the impact. In the 18 animals that did have a confirmed SD, 16 of the 18 animals $(89 \%)$ had a propagating SD in both hemispheres. The remaining two animals had a SD in one hemisphere only (one animal had a SD in the left hemisphere and the other in the right hemisphere). In these cases, the hemisphere that had an SD was used for subsequent analysis.

$\mathrm{SD}$ propagation is known to be sensitive to the non-selective NMDA receptor antagonist ketamine (Hernándéz-Cáceres et al., 1987; Kaube and Goadsby, 1994; Carlson et al., 2019). Ketamine was given systemically at least 30 min before the impact. Animals that were given saline alone displayed an impact-induced SDs in all seven animals (Fig. $4 M)$. However, ketamine reduced the incidence of the impact-induced SDs (only two out of eight animals had an SD). These data suggest that the impact-induced SDs propagate via similar mechanisms to the SDs described in more severe injuries and in other models (Rashidy-Pour et al., 1995; Sakowitz et al., 2009; Hertle et al., 2012; Reinhart and Shuttleworth, 2018; Carlson et al., 2019).

\section{Impact-induced SDs produce prolonged deficits in CBF}

CBF responses to SDs are complex, and can be dependent on species and metabolic status before the SD (for review, see Ayata and Lauritzen, 2015). We used LSCI to investigate the long-term CBF changes after an impactinduced SDs. The CBF in sham-treated animals remained relatively stable throughout the $120-$ min recording period (Fig. 5A). Baseline LSCl images were taken before impact and SDs were confirmed by the propagating wave of hypoperfusion (Fig. 4E). Images were then acquired every 15 min to monitor CBF recovery. Representative images are shown in Figure $5 A$. CBF was reduced $\sim 20-30 \%$ at 30 min and did not fully recover to baseline levels until $\sim 90$ min post-impact in both venous and tissue regions (sham $n=8$; $\mathrm{mTBI} n=8$; Fig. 5B,C; Table 1). The venous blood flow dropped to $\sim 20 \%$ of the baseline levels compared to the $30 \%$ reduction in the tissue flow, but recovered in a similar time course. The time course of the CBF recovery shown here is similar to what has been previously reported from SDs initiated by other means (von Baumgarten et al., 2008; Piilgaard and Lauritzen, 2009; Leung et al., 2013) and other closed skull impact models by Bouley and colleagues (Bouley et al., 2019).

In another cohort of animals, we investigated the stability of CBF recovery by monitoring the CBF every $24 \mathrm{~h}$ for $3 \mathrm{~d}$. Impact-induced SDs were confirmed immediately after the $\mathrm{mTBI}$ and the degree of oligemia was determined at $30 \mathrm{~min}$ post-mTBI. For these experiments we used isoflurane as the anesthetic due to the speed of onset and recovery. Isoflurane is known to reduce the frequency of SDs (Takagaki et al., 2014; Balança et al., 2017). However, we detected a SD following each impact in all four animals. A representative trace is shown in Figure $5 E$. Isoflurane did not significantly alter the hemodynamic response (Fig. $5 E$ ) or propagation rate of the SDs (Fig. 5G). However, the CBF at 30 min was significantly lower in the mTBI animals compared to the sham-treated animals $\left(F_{(4,40)}=13.38, p<0.0001\right.$; Fig. 5F). Interestingly, the $\mathrm{CBF}$ was slightly lower in the isoflurane-treated animals relative to the urethane-treated animals at 30 min postmTBI ( $\sim 70 \%$ in urethane vs $\sim 50 \%$ in isoflurane). In the $\mathrm{mTBI}$ animals the CBF at 24, 48, and $72 \mathrm{~h}$ was similar to pre-mTBI levels (Fig. 5D,F). 
A
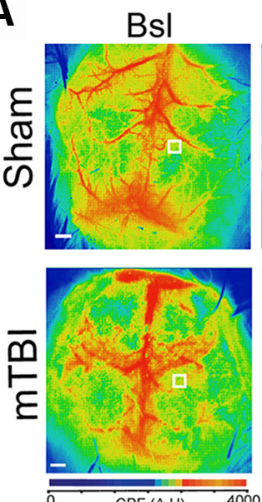

B

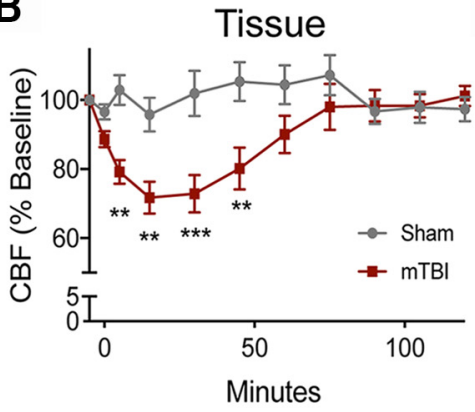

$60 \min$
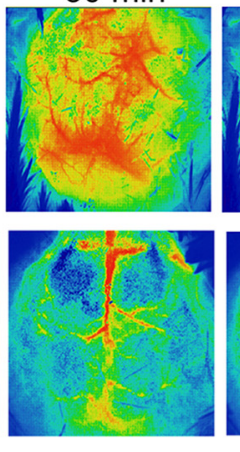

$90 \min$
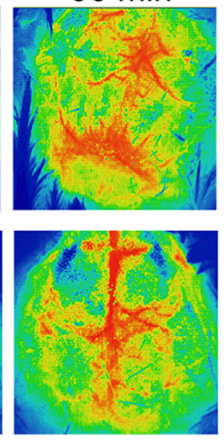

$120 \mathrm{~min}$
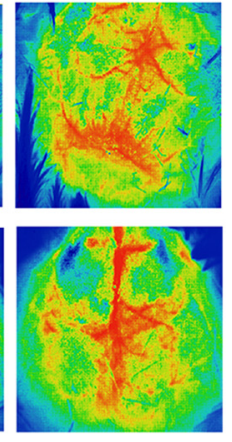

C

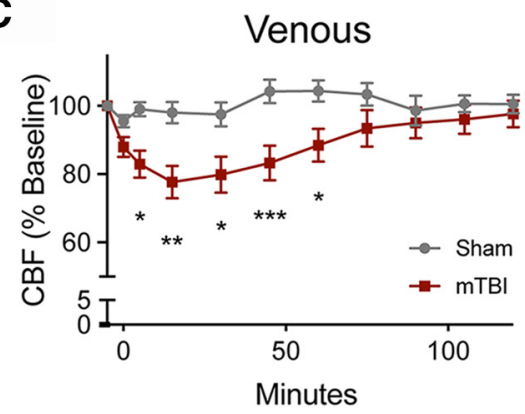

D

Bsl
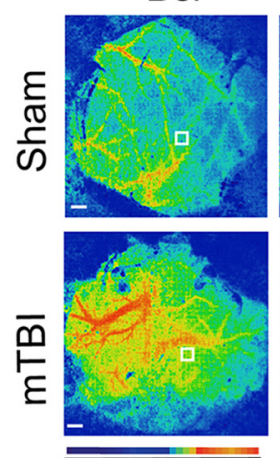

E

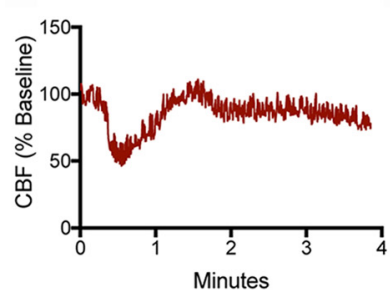

$30 \mathrm{~min}$
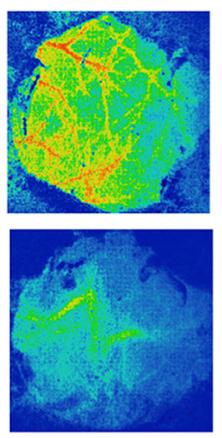

$24 \mathrm{hrs}$
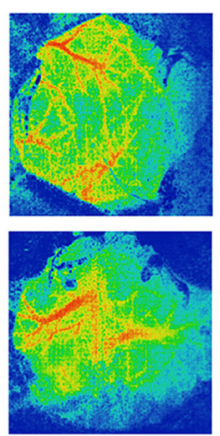

$48 \mathrm{hrs}$
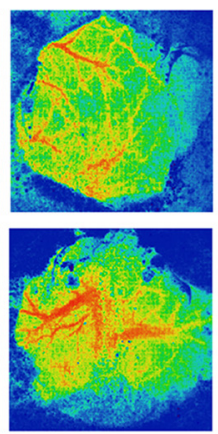

$72 \mathrm{hrs}$
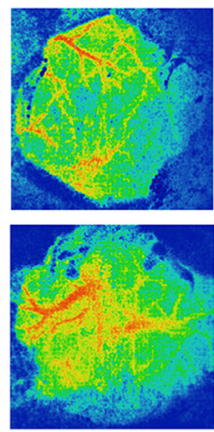

F

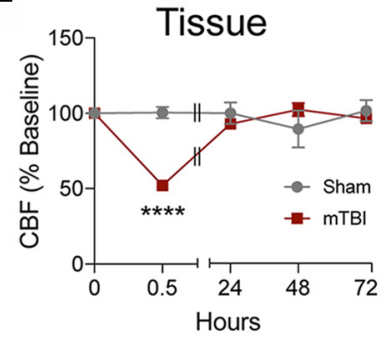

G

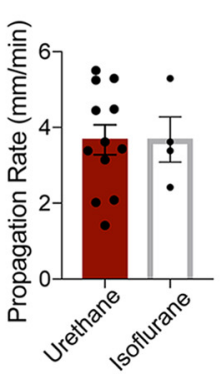

Figure 5. Impact-induced SDs are associated with long-term oligemia. Representative LSCI images of CBF from sham and mTBI animals $(\boldsymbol{A})$. Representative ROls indicate the location of repeated measures of CBF in the tissue. CBF was quantified over the 120 -min period and plotted over time for sham and mTBI animals in both tissue $(\boldsymbol{B})$ and venous $(\boldsymbol{C})$ regions. Modified cranial windows were generated to allow for repeated measures of CBF immediately after the impact and for subsequent days. Representative images before the impact, 30 min post-impact, and subsequent days are shown $(\boldsymbol{D})$. Representative ROls indicate where the CBF was quantified. Animals were anesthetized with isoflurane rather than urethane. Representative trace of the hemodynamic responses that are associated with the propagating SD in the presence of isoflurane anesthesia (E). CBF was quantified and normalized to pre-impact baseline. Using LSCI were able to confirm the SD and the peak reduction of CBF and subsequent days following the impact $(\boldsymbol{F})$. The propagation rate was also quantified in the presence of isoflurane anesthesia (G). Scale bars $=500 \mu \mathrm{m}$. 


\section{Discussion}

Our studies are the first to directly record the electrophysiological properties of SDs in a closed skull model of $\mathrm{mTBl}$ and to correlate the presence of a SD with mTBIlike behavior. The mTBI-like behavior was not long-lasting and did not result in significant long-term behavioral or cognitive deficits. The injury did not produce gross tissue damage, cell death, or astrocyte activation. The impactinduced SDs were associated with long-term reductions in CBF. Interestingly, slower impacts did not result in SDs and were not associated mTBI-like behavior. Overall our data suggest that SDs may play a critical role in mTBIs.

Our data suggest that immediately following impact, the $\mathrm{mTBI}$ animals took longer to regain movement and had fewer episodes of movement in a 10-min trial. However, this reduced mobility is not long-lasting. There were no significant differences between the movement of sham or mTBI animals in the following hours and days. This is similar to previous studies using closed skull impacts (Shen et al., 2011). Shen and colleagues showed no difference in the total distance traveled or time of movement in the hours following a closed skull weight drop model (Shen et al., 2011). However, McAteer and colleagues found that animals that had a single closed skull injury displayed fewer traveled squares six weeks post-injury (McAteer et al., 2016). This discrepancy may be due to species differences (rat vs mouse), but the injuries were similar. Behavioral and cognitive deficits are common in more severe penetrating type injuries. However, the behavioral and cognitive deficits are subtler in closed skull injuries. Using a similar closed skull impactor model, Prins and colleagues found significant deficits the novel object recognition task $24 \mathrm{~h}$ post-injury (Prins et al., 2013). However, we were unable to detect a deficit in our paradigm. This may be due to the difference in delay period before the novel object presentation. Prins and colleagues used a 24-h delay for their study and ours was only $5 \mathrm{~min}$. The 24-h delay requires memory consolidation and recall. With a similar mTBI model, Marschner and colleagues found $\mathrm{mTBI}$ animals had a stronger freezing response in the contextual fear paradigm (Marschner et al., 2019). Again, we were unable to detect a difference in our model. However, the timing of the fear-based task was slightly different between the two studies ( $3 \mathrm{~d}$ vs $24 \mathrm{~h}$ for our study). The exacerbated fear response that they found was resolved by five weeks post-mTBI. Similar to the novel object task, the increased delay between testing periods increases the difficulty of the task. Gait abnormalities are much more common in more severe penetrating injuries, especially when the motor cortex is involved (Neumann et al., 2009; Mulherkar et al., 2017; Ouyang et al., 2017; Pöttker et al., 2017; Baker et al., 2019; Kinder et al., 2019). Using a slightly more aggressive closed skull model, Mountney and colleagues could detect slight abnormalities in gait using the CatWalk analysis system, but we were unable to detect differences in our model (Mountney et al., 2017). Overall, mTBls can have a myriad of deficits in behavior, cognition, and learning and memory, but it is clear that the deficits are graded on the severity of the injury.
SDs have long been associated with moderate and severe TBls in rodents and more recently in humans (Hermann et al., 1999; Strong et al., 2002; Rogatsky et al., 2003; Fabricius et al., 2006; Hartings et al., 2008, 2009, 2011; von Baumgarten et al., 2008; Sakowitz et al., 2009; Leung et al., 2013; Sword et al., 2013; Balança et al., 2017; Hosseini-Zare et al., 2017; Carlson et al., 2019). Some rodent models of mTBls have shown the presence of SDs. However, prior studies have used more invasive techniques which often result in significant tissue swelling and/or bleeding, both of which can cause SDs (Sunami and Nakamura, 1989; Nilsson et al., 1993; Rogatsky et al., 2003; Sword et al., 2013). Recent data from Bouley and colleagues have shown propagating waves of hypoperfusion that are associated with SDs in a closed skull weight drop model (Bouley et al., 2019). In that study they used a unilateral weight drop model that consisted of a $50-\mathrm{g}$ weight being dropped from a height of $15 \mathrm{~cm}$ (Bouley et al., 2019). This means that at the site of impact the tip was traveling at $\sim 1.72 \mathrm{~m} / \mathrm{s}$. This is significantly slower than our model, but the experimental setup was much different. In their study the impact was centered over one hemisphere and it is unclear if the head was restricted. Our model seems to be less severe in that we did not detect significant neurodegeneration or seizures. In our hands, we detected SDs in 18 of the 22 animals that were impacted (82\%). The incidence of SDs in the weight drop model published by Bouley and colleagues was closer to $60 \%$ (Bouley et al., 2019). Nonetheless, in both cases the presence of SDs was associated with concussion-like behavior. Bouley and colleagues showed increased neuronal cell death and microbleeds in the injured hemisphere. In our model, we were able to detect a single microbleed in two of our eight mTBI animals and TUNELpositive nuclei in only one of $\mathrm{mTBl}$ animals. This is significantly fewer than what is reported by Bouley and colleagues. This suggests that our model is less severe than that of the weight drop model, but somewhat more efficient in generating SDs. This difference may be due to the surface area of the injury. Our studies use a larger 5-mm diameter tip that distributes the force over both hemispheres, whereas Bouley and colleagues used a 2-mm Delrin tip to transmit the weight drop energy to a single hemisphere. Another difference between the studies is when the histology was done. Bouley and others looked for apoptotic cells $48 \mathrm{~h}$ post-injury, whereas ours were done $24 \mathrm{~h}$ post-injury.

Our studies indicate that the impact-induced SDs are sensitive to ketamine inhibition. This demonstrates that the SDs generated in our model propagate via similar mechanisms to SDs in more severe injuries when there is tissue damage and bleeding. This also provides a critical starting point for the development of pharmacological interventions that target SDs directly. One caveat within our experimental design is that the behavioral data were gathered using isoflurane to allow for rapid recovery and detection of acute behavioral that may be due to the SD event itself. Isoflurane is known to reduce the frequency of SDs (Takagaki et al., 2014; Balança et al., 2017), and may confound our behavioral data. However, our extended 
CBF measurements across days did use isoflurane and all four impacts induced an SD. Furthermore, isoflurane did not alter the hemodynamic response or propagation rate. However, isoflurane did affect the peak reduction of CBF at $30 \mathrm{~min}$ post-impact $(50 \%$ in isoflurane vs $30 \%$ in urethane).

In the original manuscript describing SDs, Leao noted that these events could be initiated with a light touch to the cortical surface with a glass rod (Leao, 1944). Ex vivo and in vitro studies have supported the idea of mechanical compression and/or stretch of neuronal tissue as one possible initiator of SDs (Geddes-Klein et al., 2006; Cater et al., 2007). There is likely a critical volume of brain tissue that must depolarize in order for SD initiation (Matsura and Bures, 1971; Tang et al., 2014). In our studies, the rapid acceleration of the head could result in the compression of the entire cortex against the skull. Our LSCI data showing that SDs originate near the impact site imply a focal region of activation sufficient to reach threshold for SD initiation under the impact site. The direct mechanism that links cortical compression to neuronal depolarization is still unresolved. However, the presence of mechanical transducing ion channels is an intriguing possibility (Sachs, 2015). Ischemia itself is thought to be a critical initiator of SDs in different injury models, and is well supported by in vivo (Hartings et al., 2003; OliveiraFerreira et al., 2010, 2019; von Bornstädt et al., 2015) and ex vivo (Luhmann and Kral, 1997; Aitken et al., 1998; Andrew, 2005; Takano et al., 2007) reports. Bouley and colleagues showed that the presence of a SD was associated with increased numbers of microbleeds underneath the injury site in their concussion model (Bouley et al., 2019). The microbleeds could be a potential initiator of the SDs in that model, although this remains to be directly tested. In our studies, microbleeds were very rare, and SDs were usually generated in cortex without detectable blood brain barrier disruption.

Our data indicate that the impact-induced SDs are associated with a prolonged reduction in CBF that recover within $90 \mathrm{~min}$. This recovery remains relatively stable in the subsequent days. The peak reduction and recovery phase in our studies are very similar to those presented by Bouley and colleagues (Bouley et al., 2019). The link between long-term reduction in CBF (oligemia) and SDs has been well established in mice. However, the hemodynamic responses associated with SDs can vary widely within a given species and especially across species. In higher order animals and in humans, SDs most often trigger a propagating wave of increased CBF (hyperemia). However, both hemodynamic response can result in long-term post-SD oligemia (Hinzman et al., 2014; Ayata and Lauritzen, 2015). During this period of post-SD oligemia, there is an uncoupling between the vascular supply and the neuronal demand (Takano et al., 2007; Piilgaard and Lauritzen, 2009; Piilgaard et al., 2011; Ayata, 2013; Koide et al., 2013; Hinzman et al., 2014; Ayata and Lauritzen, 2015; Toth et al., 2016). In the wake of an SD there is a period of persistent vasoconstriction due to elevated levels of extracellular $\mathrm{K}^{+}$and a decrease in nitric oxide (Ayata and Lauritzen, 2015). Altered CBF has long been associated with concussions and can be a useful readout for long-term recovery (Len and Neary, 2011; Giza and Hovda, 2014; Keightley et al., 2014; Sours et al., 2015; Barlow et al., 2017). The use of CBF as a readout for mTBls has been limited due to the variability between individuals. Another limitation of using CBF as a diagnostic tool has traditionally been the cost and access to MRI-based imaging in a time frame that is relevant to the acute mechanisms described in the present study. However, advancement of near-infrared spectroscopy (NIRS) approaches could provide some significant advantages, and has already shown some promise as a diagnostic tool for concussions (Urban et al., 2015; Bishop and Neary, 2018; Forcione et al., 2018).

Overall, our data demonstrate the presence of SDs in mTBls and suggest that SDs may play a role in concussion-like behavior. These data provide significant insight into the cellular and physiologic mechanism that may underlie concussions.

\section{References}

Aitken PG, Tombaugh GC, Turner DA, Somjen GG (1998) Similar propagation of SD and hypoxic SD-like depolarization in rat hippocampus recorded optically and electrically. J Neurophysiol 80: $1514-1521$.

Andrew RD (2005) Neocortical brain slices. J Neurotrauma 22:277290.

Ayata C (2013) Pearls and pitfalls in experimental models of spreading depression. Cephalalgia 33:604-613.

Ayata C, Lauritzen M (2015) Spreading depression, spreading depolarizations, and the cerebral vasculature. Physiol Rev 95:953-993.

Baker EW, Kinder HA, Hutcheson JM, Duberstein KJJ, Platt SR, Howerth EW, West FD (2019) Controlled cortical impact severity results in graded cellular, tissue, and functional responses in a piglet traumatic brain injury model. J Neurotrauma 36:61-73.

Balança B, Meiller A, Bezin L, Dreier JP, Marinesco S, Lieutaud T (2017) Altered hypermetabolic response to cortical spreading depolarizations after traumatic brain injury in rats. J Cereb Blood Flow Metab 37:1670-1686.

Barlow KM, Marcil LD, Dewey D, Carlson HL, MacMaster FP, Brooks BL, Lebel RM (2017) Cerebral perfusion changes in postconcussion syndrome: a prospective controlled cohort study. J Neurotrauma 34:996-1004.

Bishop SA, Neary JP (2018) Assessing prefrontal cortex oxygenation after sport concussion with near-infrared spectroscopy. Clin Physiol Funct Imaging 38:573-585.

Boas DA, Dunn AK (2010) Laser speckle contrast imaging in biomedical optics. J Biomed Opt 15:011109.

Bouley J, Chung DY, Ayata C, Brown RH Jr, Henninger N (2019) Cortical spreading depression denotes concussion injury. J Neurotrauma 36:1008-1017.

Brent DA, Max J (2017) Psychiatric sequelae of concussions. Curr Psychiatry Rep 19:108-116.

Bures J, Buresova O (1960) Activation of latent foci of spreading cortical depression in rats. J Neurophysiol 23:225-236.

Buresova O (1956) Modification of cerebral blood supply in rats during spreading electroencephalographic depression. Cesk Fysiol 5:352-361.

Cao Y, Welch KMA, Aurora S, Vikingstad EM (1999) Functional MRI-BOLD of visually triggered headache in patients with migraine. Arch Neurol 56:548-554.

Carlson AP, Abbas M, Alunday RL, Qeadan F, Shuttleworth CW (2019) Spreading depolarization in acute brain injury inhibited by ketamine: a prospective, randomized, multiple crossover trial. J Neurosurg 130:1513-1519. 
Cater HL, Gitterman D, Davis SM, Benham CD, Morrison B 3rd, Sundstrom LE (2007) Stretch-induced injury in organotypic hippocampal slice cultures reproduces in vivo post-traumatic neurodegeneration: role of glutamate receptors and voltage-dependent calcium channels. J Neurochem 101:434-447.

Chen SP, Qin T, Seidel JL, Zheng Y, Eikermann M, Ferrari MD, van den Maagdenberg AMJM, Moskowitz MA, Ayata C, EikermannHaerter K (2017) Inhibition of the P2X7-PANX1 complex suppresses spreading depolarization and neuroinflammation. Brain 140:1643-1656.

Chodobski A, Zink BJ, Szmydynger-Chodobska J (2011) Blood-brain barrier pathophysiology in traumatic brain injury. Transl Stroke Res 2:492-516.

Clay MB, Glover KL, Lowe DT (2013) Epidemiology of concussion in sport: a literature review. J Chiropr Med 12:230-251.

DeKosky ST, Blennow K, Ikonomovic MD, Gandy S (2013) Acute and chronic traumatic encephalopathies: pathogenesis and biomarkers. Nat Rev Neurol 9:192-200.

Denny-Brown DE, Russell WR (1941) Experimental concussion. Proc R Soc Med 34:691-692

Dietrich JWD, Truettner J, Prado R, Stagliano NE (2000) Thromboembolic events lead to cortical spreading depression and expression of C-Fos, brain-derived neurotrophic factor, glial fibrillary acidic protein, and heat shock protein 70 MRNA in rats. J Cereb Blood Flow Metab 20:103-111.

Dreier JP, Fabricius M, Ayata C, Sakowitz OW, Shuttleworth CW, Dohmen C, Graf R, Vajkoczy P, Helbok R, Suzuki M, Schiefecker AJ, Major S, Winkler MK, Kang EJ, Milakara D, Oliveira-Ferreira Al, Reiffurth C, Revankar GS, Sugimoto K, Dengler NF, et al. (2017) Recording, analysis, and interpretation of spreading depolarizations in neurointensive care: review and recommendations of the COSBID research group. J Cereb Blood Flow Metab 37:15951625.

Ebine T, Toriumi H, Shimizu T, Unekawa M, Takizawa T, Kayama Y, Shibata M, Suzuki N (2016) Alterations in the threshold of the potassium concentration to evoke cortical spreading depression during the natural estrous cycle in mice. Neurosci Res 112:57-62.

Enger R, Tang W, Vindedal GF, Jensen V, Johannes Helm P, Sprengel R, Looger LL, Nagelhus EA (2015) Dynamics of ionic shifts in cortical spreading depression. Cereb Cortex 25:4469-4476.

Fabricius M, Fuhr S, Bhatia R, Boutelle M, Hashemi P, Strong AJ, Lauritzen M (2006) Cortical spreading depression and peri-infarct depolarization in acutely injured human cerebral cortex. Brain 129:778-790.

Fifkova E, Bures J, Koshtoyants Ok, Krivanek J, Weiss T (1961) Leao's spreading depression in the cerebellum of rat. Experientia 17:572-573.

Forcione M, Colonnese C, Belli A (2018) Cerebral hemodynamic influences in task-related functional magnetic resonance imaging and near-infrared spectroscopy in acute sport-related concussion: a review. J Imaging 4:59.

Geddes-Klein DM, Schiffman KB, Meaney DF (2006) Mechanisms and consequences of neuronal stretch injury in vitro differ with the model of trauma. J Neurotrauma 23:193-204.

Giri BK, Krishnappa IK, Bryan RM Jr, Robertson C, Watson J (2000) Regional cerebral blood flow after cortical impact injury complicated by a secondary insult in rats. Stroke 31:961-967.

Giza CC, Hovda DA (2014) The new neurometabolic cascade of concussion. Neurosurgery 75:S24-S33.

Gorelova NA, Bures J (1983) Spiral waves of spreading depression in the isolated chicken retina. J Neurobiol 14:353-363.

Guedes R, Barreto JM (1992) Effect of anesthesia on the propagation of cortical spreading depression in rats. Braz $\mathrm{J}$ Med Biol Res 25:393-397.

Hadjikhani N, Sanchez Del Rio M, Wu O, Schwartz D, Bakker D, Fischl B, Kwong KK, Cutrer FM, Rosen BR, Tootell RB, Sorensen AG, Moskowitz MA (2001) Mechanisms of migraine aura revealed by functional MRI in human visual cortex. Proc Natl Acad Sci USA 98:4687-4692.
Hansen AJ, Quistorff B, Gjedde A (1980) Relationship between local changes in cortical blood flow and extracellular $\mathrm{K}+$ during spreading depression. Acta Physiol Scand 109:1-6.

Hartings JA, Rolli ML, Lu XCM, Tortella FC (2003) Delayed secondary phase of peri-infarct depolarizations after focal cerebral ischemia: relation to infarct growth and neuroprotection. J Neurosci23: 11602-11610.

Hartings JA, Gugliotta M, Gilman C, Strong AJ, Tortella FC, Bullock MR (2008) Repetitive cortical spreading depolarizations in a case of severe brain trauma. Neurol Res 30:876-882.

Hartings J, Strong AJ, Fabricius M, Manning A, Bhatia R, Dreier JP, Mazzeo AT, Tortella FC, Bullock MR; Co-Operative Study of Brain Injury Depolarizations (2009) Spreading depolarizations and late secondary insults after traumatic brain injury. J Neurotrauma 1866: 1857-1866.

Hartings JA, Bullock MR, Okonkwo DO, Murray LS, Murray GD, Fabricius M, Maas Al, Woitzik J, Sakowitz O, Mathern B, Roozenbeek B, Lingsma H, Dreier JP, Puccio AM, Shutter LA, Pahl C, Strong AJ; Co-Operative Study on Brain Injury Depolarisations (2011) Spreading depolarisations and outcome after traumatic brain injury: a prospective observational study. Lancet Neurol 10:1058-1064

Hermann DM, Mies G, Hossmann K (1999) Expression of c-fos, junB, c-jun, MKP-1 and hsp72 following traumatic neocortical lesions in rats--relation to spreading depression. Neuroscience 88:599-608.

Hernándéz-Cáceres J, Macias-González R, Brozek G, Bures J (1987) Systemic ketamine blocks cortical spreading depression but does not delay the onset of terminal anoxic depolarization in rats. Brain Res 437:360-364.

Hertle DN, Dreier JP, Woitzik J, Hartings JA, Bullock R, Okonkwo DO, Shutter LA, Vidgeon S, Strong AJ, Kowoll C, Dohmen C, Diedler J, Veltkamp R, Bruckner T, Unterberg AW, Sakowitz OW; Cooperative Study of Brain Injury Depolarizations (COSBID) (2012) Effect of analgesics and sedatives on the occurrence of spreading depolarizations accompanying acute brain injury. Brain 135:23902398.

Hinzman JM, Andaluz N, Shutter LA, Okonkwo DO, Pahl C, Strong AJ, Dreier JP, Hartings JA (2014) Inverse neurovascular coupling to cortical spreading depolarizations in severe brain trauma. Brain 137:2960-2972.

Hosseini-Zare MS, Gu F, Abdulla A, Powell S, Žiburkus J (2017) Effects of experimental traumatic brain injury and impaired glutamate transport on cortical spreading depression. Exp Neurol 295: 155-161.

Jones A, Jarvis P (2017) Review of the potential use of blood neuro-biomarkers in the diagnosis of mild traumatic brain injury. Clin Exp Emerg Med 4:121-127.

Katayama Y, Becker DP, Tamura T, Hovda DA (1990) Massive increases in extracellular potassium and the indiscriminate release of glutamate following concussive brain injury. J Neurosurg 73: 889-900.

Kaube H, Goadsby PJ (1994) Anti-migraine compounds fail to modulate the propagation of cortical spreading depression in the cat. Eur Neurol 34:30-35.

Keightley ML, Saluja RS, Chen JK, Gagnon I, Leonard G, Petrides M, Ptito A (2014) A functional magnetic resonance imaging study of working memory in youth after sports-related concussion: is it still working? J Neurotrauma 31:437-451.

Kinder HA, Baker EW, Wang S, Fleischer CC, Howerth EW, Duberstein KJ, Mao H, Platt SR, West FD (2019) Traumatic brain injury results in dynamic brain structure changes leading to acute and chronic motor function deficits in a pediatric piglet model. J Neurotrauma 36:2930-2942.

Koide M, Sukhotinsky I, Ayata C, Wellman GC (2013) Subarachnoid hemorrhage, spreading depolarizations and impaired neurovascular coupling. Stroke Res Treat 2013:819340.

Krivanek J (1961) Some metabolic changes accompanying Leao's spreading cortical depression in the rat. J Neurochem 6:183-189.

Kubota M, Nakamura T, Sunami K, Ozawa Y, Namba H, Yamaura A, Makino H (1989) Changes of local cerebral glucose utilization, DC 
potential and extracellular potassium concentrations in experimental head injury of varying severity. Neurosurg Rev 12:393-399.

Kucharz K, Lauritzen M (2018) CaMKII-dependent endoplasmic reticulum fission by whisker stimulation and during cortical spreading depolarization. Brain 141:1049-1062.

Lauritzen M, Olsen TS, Lassen NA, Paulson OB (1983) Changes in regional cerebral blood flow during the course of classic migraine attacks. Ann Neurol 13:633-641.

Leao AAP (1944) Spreading depression of activity in the cerebral cortex depression. J Neurophysiol 7:359-390.

Len TK, Neary JP (2011) Cerebrovascular pathophysiology following mild traumatic brain injury. Clin Physiol Funct Imaging 31:85-93.

Leung LY, Wei G, Shear D. a, Tortella FC (2013) The acute effects of hemorrhagic shock on cerebral blood flow, brain tissue oxygen tension, and spreading depolarization following penetrating ballistic-like brain injury. J Neurotrauma 30:1288-1298.

Lighthall JW (1988) Controlled cortical impact: a new experimental brain injury model. J Neurotrauma 5:1-15.

Lindquist BE, Shuttleworth CW (2014) Spreading depolarizationinduced adenosine accumulation reflects metabolic status in vitro and in vivo. J Cereb Blood Flow Metab 34:1779-1790.

Lindquist B, Shuttleworth CW (2017) Evidence that adenosine contributes to Leao's spreading depression in vivo. J Cereb Blood Flow Metab 37:1656-1669.

Luhmann HJ, Kral T (1997) Hypoxia-induced dysfunction in developing rat neocortex. J Neurophysiol 78:1212-1221.

Main BS, Sloley SS, Villapol S, Zapple DN, Burns MP (2017) A mouse model of single and repetitive mild traumatic brain injury. J Vis Exp 124: e55713.

Marschner L, Schreurs A, Lechat B, Mogensen J, Roebroek A, Ahmed T, Balschun D (2019) Single mild traumatic brain injury results in transiently impaired spatial long-term memory and altered search strategies. Behav Brain Res 365:222-230.

Martin H, Warner DS, Todd MM (1994) Effects of glycine receptor antagonism on spreading depression in the rat. Neurosci Lett 180:285-289.

Matsura T, Bures J (1971) The minimum volume of depolarized neuronal tissue required for triggering cortical spreading depression in rat. Exp Brain Res 12:238-249.

Maxson SC, Cowen JS (1977) Effect of cortical spreading depression on audiogenic seizure priming of C57BL/6 mice. Pharmacol Biochem Behav 6:349-350.

McAteer KM, Corrigan F1, Thornton E1, Turner RJ1, Vink R (2016) Short and long term behavioral and pathological changes in a novel rodent model of repetitive mild traumatic brain injury. PLoS One 11:e0160220.

McLaughlin MR, Marion DW (1996) Cerebral blood flow and vasoresponsivity within and around cerebral contusions. J Neurosurg 85:871-76.

Meyer JS, Denny-Brown D (1955) Cerebral circulation in brain injury. II. Cerebral concussion. Electroencephalogr Clin Neurophysiol 7:529-544.

Miao P, Lu H, Liu Q, Li Y, Tong S (2011) Laser speckle contrast imaging of cerebral blood flow in freely moving animals. J Biomed Opt 16:090502.

Monakhov KK, Fifkova E, Bures J (1962) Vertical disruption of the slow wave potential change of spreading depression in the cerebral cortex of the rat. Physiol Bohemoslov 11:269-276.

Mountney A, Boutté AM, Cartagena CM, Flerlage WF, Johnson WD, Rho C, Lu XC, Yarnell A, Marcsisin S, Sousa J, Vuong C, Zottig V, Leung LY, Deng-Bryant Y, Gilsdorf J, Tortella FC, Shear DA (2017) Functional and molecular correlates after single and repeated rat closed-head concussion: indices of vulnerability after brain injury. J Neurotrauma 34:2768-2789.

Mulherkar S, Firozi K, Huang W, Uddin MD, Grill RJ, Costa-Mattioli M, Robertson C, Tolias KF (2017) RhoA-ROCK inhibition reverses synaptic remodeling and motor and cognitive deficits caused by traumatic brain injury. Sci Rep 7:10689.
Neumann M, Wang Y, Kim S, Hong SM, Jeng L, Bilgen M, Liu J (2009) Assessing gait impairment following experimental traumatic brain injury in mice. J Neurosci Methods 176:34-44.

Nilsson P, Hillered L, Olsson Y, Sheardown MJ, Hansen AJ (1993) Regional changes in interstitial $\mathrm{K}+$ and $\mathrm{Ca} 2+$ levels following cortical compression contusion trauma in rats. J Cereb Blood Flow Metab 13:183-192.

Oliveira-Ferreira Al, Milakara D, Alam M, Jorks D, Major S, Hartings JA, Lückl J, Martus P, Graf R, Dohmen C, Bohner G, Woitzik J, Dreier JP; COSBID study group (2010) Experimental and preliminary clinical evidence of an ischemic zone with prolonged negative DC shifts surrounded by a normally perfused tissue belt with persistent electrocorticographic depression. J Cereb Blood Flow Metab 30:1504-1519.

Oliveira-Ferreira Al, Major S, Przesdzing I, Kang EJ, Dreier JP (2019) Spreading depolarizations in the rat endothelin-1 model of focal cerebellar ischemia. J Cereb Blood Flow Metab. Advance online publication. Retrieved July 7, 2019. doi:10.1177/ $0271678 \times 19861604$.

Ouyang W, Yan Q, Zhang Y, Fan Z (2017) Moderate injury in motorsensory cortex causes behavioral deficits accompanied by electrophysiological changes in mice adulthood. PLoS One 12: e0171976.

Paschen G (1984) Regional changes of blood flow, glucose, and ATP content determined on brain sections during a single passage of spreading depression in rat brain cortex. Exp Neurol 84:249-258.

Piilgaard H, Lauritzen M (2009) Persistent increase in oxygen consumption and impaired neurovascular coupling after spreading depression in rat neocortex. J Cereb Blood Flow Metab 29:15171527.

Piilgaard H, Witgen BM, Rasmussen P, Lauritzen M (2011) Cyclosporine A, FK506, and NIM811 ameliorate prolonged CBF reduction and impaired neurovascular coupling after cortical spreading depression. J Cereb Blood Flow Metab 31:1588-1598.

Pöttker B, Stöber F, Hummel R, Angenstein F, Radyushkin K, Goldschmidt J, Schäfer MKE (2017) Traumatic brain injury causes long-term behavioral changes related to region-specific increases of cerebral blood flow. Brain Struct Funct 222:4005-4021.

Prins ML, Alexander D, Giza CC, Hovda DA (2013) Repeated mild traumatic brain injury: mechanisms of cerebral vulnerability. $\mathrm{J}$ Neurotrauma 30:30-38.

Rashidy-Pour A, Motaghed-Larijani Z, Bures J (1995) Tolerance to ketamine-induced blockade of cortical spreading depression transfers to MK-801 but not to AP5 in rats. Brain Res 693:64-69.

Reinhart KM, Shuttleworth CW (2018) Ketamine reduces deleterious consequences of spreading depolarizations. Exp Neurol 305:12128.

Rogatsky GG, Sonn J, Kamenir Y, Zarchin N, Mayevsky A (2003) Relationship between intracranial pressure and cortical spreading depression following fluid percussion brain injury in rats. J Neurotrauma 20:1315-1325.

Ruediger W, Beresova O, Fifkova E (1962) Effect of the spreading depression activity (Leao's phenomenon) in the cerebral cortex on the discharge activity of single neurons in the diencephalon of rats. Acta Biol Med Ger 9:371-985.

Sachs F (2015) Mechanical transduction by ion channels: a cautionary tale. World J Neurol 5:74.

Sakowitz OW, Kiening KL, Krajewski KL, Sarrafzadeh AS, Fabricius M, Strong AJ, Unterberg AW, Dreier JP (2009) Preliminary evidence that ketamine inhibits spreading depolarizations in acute human brain injury. Stroke 40:e519-e523.

Santos E, León F, Silos H, Sanchez-Porras R, Shuttleworth CW, Unterberg A, Sakowitz OW (2016) Incidence, hemodynamic, and electrical characteristics of spreading depolarization in a swine model are affected by local but not by intravenous application of magnesium. J Cereb Blood Flow Metab 36:2051-2057.

Shen H, Harvey BK, Chiang YH, Pick CG, Wang Y (2011) Methamphetamine potentiates behavioral and electrochemical responses after mild traumatic brain injury in mice. Brain Res 1368:248-253. 
Shitaka Y, Tran HT, Bennett RE, Sanchez L, Levy MA, Dikranian K, Brody DL (2011) Repetitive closed-skull traumatic brain injury in mice causes persistent multifocal axonal injury and microglia reactivity. J Neuropathol Exp Neurol 70:551-567.

Silver JM, Mcallister TW, Arciniegas DB (2009) Depression and cognitive complaints following mild traumatic brain injury. Am J Psychiatry 166:653-661.

Sours C, Zhuo J, Roys S, Shanmuganathan K, Gullapalli RP (2015) Disruptions in resting state functional connectivity and cerebral blood flow in mild traumatic brain injury patients. PLoS One 10: e0134019.

Strong AJ, Fabricius M, Boutelle MG, Hibbins SJ, Hopwood SE, Jones R, Parkin MC, Lauritzen M (2002) Spreading and synchronous depressions of cortical activity in acutely injured human brain. Stroke 33:2738-2743.

Strong AJ, Anderson PJ, Watts HR, Virley DJ, Lloyd A, Irving EA, Nagafuji T, Ninomiya M, Nakamura H, Dunn AK, Graf R (2007) Peri-infarct depolarizations lead to loss of perfusion in ischaemic gyrencephalic cerebral cortex. Brain 130:995-1008.

Sunami K, Nakamura T (1989) Spreading depression following experimental head injury in the rat. Neurol Med Chir (Tokyo) 29:975980.

Sword J, Masuda T, Croom D, Kirov SA (2013) Evolution of neuronal and astroglial disruption in the peri-contusional cortex of mice revealed by in vivo two-photon imaging. Brain 136:1446-1461.

Tagge CA, Fisher AM, Minaeva OV, Gaudreau-Balderrama A, Moncaster JA, Zhang X-L, Wojnarowicz MW, Casey N, Lu H, KokikoCochran ON, Saman S, Ericsson M, Onos KD, Veksler R, Senatorov VV, Kondo A, Zhou XZ, Miry O, Vose LR, Gopaul KR (2018) Concussion, microvascular injury, and early tauopathy in young athletes after impact head injury and an impact concussion mouse model. Brain 141:422-458.

Takagaki M, Feuerstein D, Kumagai T, Gramer M, Yoshimine T, Graf R (2014) Isoflurane suppresses cortical spreading depolarizations compared to propofol--implications for sedation of neurocritical care patients. Exp Neurol 252:12-17.

Takahashi H, Manaka S, Sano K (1981) Changes in extracellular potassium concentration in cortex and brain stem during the acute phase of experimental closed head injury. J Neurosurg 55:708717.

Takano T, Tian GF, Peng W, Lou N, Lovatt D, Hansen AJ, Kasischke KA, Nedergaard M (2007) Cortical spreading depression causes and coincides with tissue hypoxia. Nat Neurosci 10:754-762.

Tang YT, Mendez JM, Theriot JJ, Sawant PM, López-Valdés HE, Ju YS, Brennan KC (2014) Minimum conditions for the induction of cortical spreading depression in brain slices. J Neurophysiol 112: 2572-2579.
Toth P, Szarka N, Farkas E, Ezer E, Czeiter E, Amrein K, Ungvari Z, Hartings JA, Buki A, Koller A (2016) Traumatic brain injury-induced autoregulatory dysfunction and spreading depression-related neurovascular uncoupling: pathomechanisms, perspectives, and therapeutic implications. Am J Physiol Heart Circ Physiol 311:H1118H1131.

Tschirgi RD, Inanaga K, Taylor JL, Walker RM, Sonnenschein RR (1957) Changes in cortical pH and blood flow accompanying spreading cortical depression and convulsion. Am J Physiol 190: 557-562.

Urban KJ, Barlow KM, Jimenez JJ, Goodyear BG, Dunn JF (2015) Functional near-infrared spectroscopy reveals reduced interhemispheric cortical communication after pediatric concussion. J Neurotrauma $32: 833-840$.

von Baumgarten L, Trabold R, Thal S, Back T, Plesnila N (2008) Role of cortical spreading depressions for secondary brain damage after traumatic brain injury in mice. $\mathrm{J}$ Cereb Blood Flow Metab 28:1353-1360.

von Bornstädt D, Houben T, Seidel JL, Zheng Y, Dilekoz E, Qin T, Sandow N, Kura S, Eikermann-Haerter K, Endres M, Boas DA, Moskowitz MA, Lo EH, Dreier JP, Woitzik J, Sakadžić S, Ayata C (2015) Supply-demand mismatch transients in susceptible periinfarct hot zones explain the origins of spreading injury depolarizations. Neuron 85:1117-1131.

Ward AA Jr (1964) The physiology of concussion. Clin Neurosurg 12:95-111.

Ward R, Sinnett EE (1971) Spreading cortical depression and audiogenic seizures in mice. Exp Neurol 31:437-443.

Watanabe N, Noriaki W (2002) The mechanism and pathophysiology of rat cerebral concussion: changes in RCBF, ECoG, SPC following skull impact. J Soc Toho University 49:23-30.

West M, Parkinson D, Havlicek V (1982) Spectral analysis of the electroencephalographic response in experimental concussion in the rat. Electroencephalogr Clin Neurophysiol 53:192-200.

Yang O, Cuccia D, Choi B (2011) Real-time blood flow visualization using the graphics processing unit. J Biomed Opt 16:016009.

Yoshino A, Hovda DA, Kawamata T, Katayama Y, Becker DP (1991) Dynamic changes in local cerebral glucose utilization following cerebral concussion in rats: evidence of a hyper- and subsequent hypometabolic state. Brain Res 561:106-119.

Zachar J, Zacharová D (1958) Mechanical energy as a causative agent of spreading depression. Cesk Fysiol 7:189-190.

Zachar J, Zacharová D (1961) Subthreshold changes at the site of initiation of spreading cortical depression by mechanical stimuli. Clin Neurophysiol 13:896-904. 